\title{
Phase-based cortical synchrony is affected by prematurity
}

Pauliina Yrjölä, Susanna Stjerna, Matias Palva, Sampsa Vanhatalo* \& Anton Tokariev*

* These authors contributed equally

Author details

\section{Pauliina Yrjölä (corresponding author)}

1. BABA center, Department of Clinical Neurophysiology, Childrens' Hospital, Helsinki University Hospital and University of Helsinki, Helsinki, Finland

2. Department of Neuroscience and Biomedical Engineering, Aalto University, Helsinki, Finland

3. Neuroscience center, Helsinki Institute of Life Science, University of Helsinki, Helsinki, Finland

Correspondence

BABA center, Childrens' Hospital

Helsinki University Hospital

P.O.Box 281, Stenbäckinkatu 11, 00029 HUS, Helsinki, Finland.

Email: pauliina.yrjola@aalto.fi

Competing interests

The author declares that no competing interests exist.

2. Susanna Stjerna

1. BABA center, Department of Clinical Neurophysiology, Childrens' Hospital, Helsinki University Hospital and University of Helsinki, Helsinki, Finland

2. Neuroscience center, Helsinki Institute of Life Science, University of Helsinki, Helsinki, Finland

Competing interests

The author declares that no competing interests exist.

3. J. Matias Palva

1. Department of Neuroscience and Biomedical Engineering, Aalto University, Helsinki, Finland

2. Neuroscience center, Helsinki Institute of Life Science, University of Helsinki, Helsinki, Finland

3. Centre for Cognitive Neuroimaging, Institute of Neuroscience and Psychology, University of Glasgow, United Kingdom

Competing interests

The author declares that no competing interests exist.

4. Sampsa Vanhatalo 
1. BABA center, Department of Clinical Neurophysiology, Childrens' Hospital, Helsinki University Hospital and University of Helsinki, Helsinki, Finland

2. Neuroscience center, Helsinki Institute of Life Science, University of Helsinki, Helsinki, Finland

Competing interests

The author declares that no competing interests exist.

\section{Anton Tokariev (corresponding author)}

1. BABA center, Department of Clinical Neurophysiology, Childrens' Hospital, Helsinki University Hospital and University of Helsinki, Helsinki, Finland

2. Neuroscience center, Helsinki Institute of Life Science, University of Helsinki, Helsinki, Finland

\section{Correspondence}

BABA center, Childrens' Hospital

Helsinki University Hospital

P.O.Box 281, Stenbäckinkatu 11, 00029 HUS, Helsinki, Finland.

Email: anton.tokariev@helsinki.fi

Competing interests

The author declares that no competing interests exist.

Acknowledgements: This work was supported by the Finnish Pediatric Foundation, the Finnish Academy (313242, 288220, 321235), Juselius Foundation, Aivosäätiö, Neuroscience Center at University of Helsinki, as well as Helsinki University Central Hospital 


\section{Phase-based cortical synchrony is affected by prematurity}

\section{Abstract}

63 Inter-areal synchronization by phase-phase correlations (PPC) of cortical oscillations

64 mediates many higher neurocognitive functions, which are often affected by prematurity, a

65 globally prominent neurodevelopmental risk factor. Here, we used electroencephalography

66 (EEG) to examine brain-wide cortical PPC networks at term-equivalent age, comparing human

67 infants after early prematurity to a cohort of healthy controls. We found that prematurity

68 affected these networks in a sleep state-specific manner, and the differences between groups

69 were also frequency-selective, involving brain-wide connections. The strength of

70 synchronization in these networks was predictive of clinical outcomes in the preterm infants.

71 These findings show that prematurity affects PPC networks in a clinically significant manner

72 suggesting early functional biomarkers of later neurodevelopmental compromise to be used

73 in clinical and translational studies after early neonatal adversity.

74

75 Keywords: neonatal EEG, brain networks, NICU, brain monitoring, preterm infant, neurodevelopment, phase coupling, intrinsic coupling modes 
bioRxiv preprint doi: https://doi org/10.1101/2021.02 15.431226; this version posted February 18,2021 . The copyright holder for this preprint (which was not certified by peer review) is the author/funder, who has granted bioRxiv a license to display the preprint in perpetuity. It is made available under aCC-BY 4.0 International license.

Phase-based cortical synchrony is affected by prematurity

\section{Introduction}

Approximately $10 \%$ of infants are born preterm, which inflicts lifelong disabilities in many key brain functions, including vision, learning, and language processing (Johnson \& Marlow, 2017; WHO, 2012). Many of these functional abnormalities arise from the impacts that prematurity has on neuronal networks. Recent studies have demonstrated both structural (Batalle et al., 2017; Guo et al., 2017) and functional (Tokariev et al., 2019a; Tokariev et al., 2019b; Tóth et al., 2017) effects of prematurity, some of which are shown to predict later neurodevelopmental outcomes.

Prematurity implies that the infants spend a part or all of their third trimester of gestation in an unnatural environment, ex utero. This time window is known to be characterized by the growth of brain networks driven by a combination of genetic and activity-dependent mechanisms (Luhmann et al., 2016; Molnár et al., 2020). The early cortical activity can be recorded with scalp electroencephalography (EEG) and consists of spontaneous intermittent bursts, which provide an early mechanism for inter-areal temporal correlations and define functional cortical networks (Vanhatalo \& Kaila, 2006). Therefore, the early cortical activity is a driver, guide, and biomarker of the development of brain networks.

The functional cortical networks can be characterized by quantifying relationships between phase or amplitude attributes of neural signals from distinct brain regions. Prior research on neonatal EEG (Omidvarnia et al., 2014; Tokariev et al., 2019a; Tokariev et al., 2019b) have often focused on the amplitude-amplitude correlations (AACs) that reflect co-modulation of overall neuronal activity and gross cortical excitability over periods of seconds (Engel et al., 2013; Hipp et al., 2012; Palva \& Palva, 2011; Tewarie et al., 2019). The other commonly used measure of neuronal interactions is phase-phase correlation (PPC) that is considered to reflect a spatiotemporally accurate mechanism of inter-areal communication. PPC is thought to arise from subsecond timing relationships in neuronal spiking (Palva \& Palva, 2011; 
104 Vidaurre et al., 2018; Womelsdorf et al., 2007), hence being able to support dynamic 105 integration in neuronal ensembles underlying several higher-level brain functions (Bressler \&

106 Menon, 2010; Palva \& Palva, 2011). Moreover, it is now well known that the brain operates 107 concurrently at multiple frequencies, giving rise to multiplex networks shaped by concerted 108 actions of different coupling mechanisms in several frequency bands (De Domenico et al., 109 2016; Siebenhühner et al., 2016).

111 Our recent study suggests that PPC networks link to neurological performance (Tokariev et 112 al., 2019b). However, the spatial and spectral extent of these findings, as well as their clinical 113 correlates have remained unclear. Here, we aimed to assess how the large-scale cortical PPC 114 networks are affected by preterm birth of human infants. We analysed EEG recordings from a 115 large cohort of preterm and healthy control infants using an infant-specific source modelling116 based analysis pipeline that allows non-invasive assessment of functional networks at the 117 level of cortical sources. We asked whether prematurity leads to changes in the cortical 118 networks that are linked to sleep state, brain area or oscillation frequency. Moreover, we 119 wanted to study if prematurity-related changes in cortical networks would have clinical 120 significance, i.e., be predictive of clinical neurological performance of the infants by the time of recording and/or later during childhood. 
bioRxiv preprint doi: https:/doi org/10.1101/2021.02 15.431226. this version posted February 18, 2021. The copyright holder for this preprint (which was not certified by peer review) is the author/funder, who has granted bioRxiv a license to display the preprint in perpetuity. It is made available under aCC-BY 4.0 International license.

Phase-based cortical synchrony is affected by prematurity

\section{Results}

123 To characterize effects of prematurity on early cortical networks, we recorded multichannel 124 scalp EEG at term-equivalent age from a group of infants born extremely preterm $(E P, N=$ 125 46), as well as from a group of full-term healthy controls $(\mathrm{HC}, \mathrm{N}=67)$. The PPC cortical 126 networks were computed from source-reconstructed EEG data for active (AS) and quiet sleep 127 (QS) within 21 narrow frequency bands covering the physiologically relevant range of 0.4-22 $\mathrm{Hz}$ (Vanhatalo et al., 2005). To evaluate the impact of prematurity on cortical networks as a

129 function of frequency, we estimated the extent of significant network differences between EP 130 and $\mathrm{HC}$ groups at each specific frequency. Finally, to define patterns which are linked to infant 131 neurological performance, we correlated the PPC networks of the EP group to key 132 neurological scores at term age and neurocognitive assessments at two years of age. We 133 described the extent of patterns that are different between groups or correlate to outcomes as 134 a fraction of statistically significant connections $(K)$ relative to the whole network (Palva et al., 135 2010). The overall analytical flow is shown on Figure 1 and described in detail in the Methods section. 
bioRxiv preprint doi: https://doi. org/10.1101/2021.02.15.431226 - this version posted February 18, 2021. The copyright holder for this preprint (which was not certified by peer review) is the author/funder, who has granted bioRxiv a license to display the preprint in perpetuity. It is made available under aCC-BY 4.0 International license.

\section{Phase-based cortical synchrony is affected by prematurity}

a

Data acquisition Narrow-band filtering Source reconstruction Network Analysis

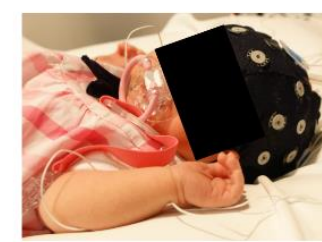

Active sleep (AS)

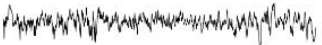

Quiet sleep (QS)

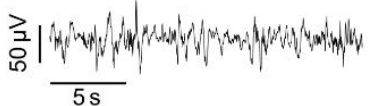

b

Group statistics

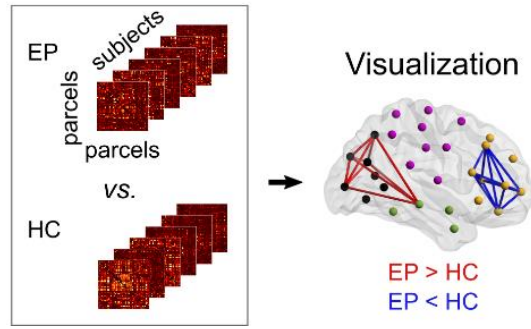

C

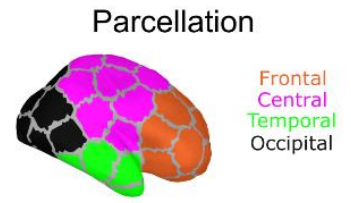

Parcel signals [3.1 Hz]

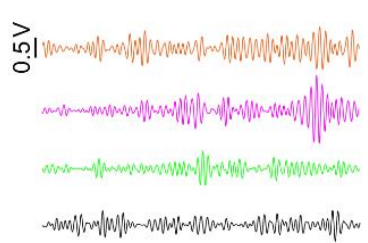

Phase-phase correlations

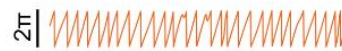

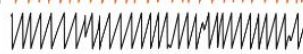

Adjacency matrix

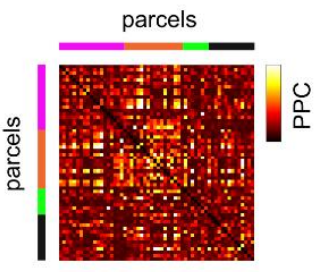

Figure 1. Outline of the study design and analyses. (a) EEG recordings of day-time sleep were acquired from early preterm (EP) and healthy control (HC) cohorts. The recordings were classified into active (AS) and quiet sleep (QS), and 5-minute-long epochs were constructed for both sleep states. The selected epochs were filtered into 21 narrow frequency bands of semi-equal length on a logarithmic scale and converted to cortical source signals applying a realistic infant head model with 58 cortical parcels. Functional connectivity analysis was applied on the parcel signals by computing phase-phase correlations (PPCs) with the debiased phase lag index, yielding subject-specific connectivity matrices for both sleep states and all frequency bands. (b) Statistical group differences in connectivity strength were computed (Wilcoxon rank sum test) for both sleep states and each frequency band. The edges portraying significant differences for two contrasts EP $>\mathrm{HC}$ (red) and $\mathrm{EP}<\mathrm{HC}$ (blue) were then visualized. (c) Finally, correlations of PPC strengths to newborn neurological and 2-year neurocognitive assessment scores were investigated (Spearman correlation). The edges related to significant clinical correlation were visualized. 
bioRxiv preprint doi: https://doi org/10.1101/2021.02 15.431226; this version posted February 18, 2021. The copyright holder for this preprint (which was not certified by peer review) is the author/funder, who has granted bioRxiv a license to display the preprint in perpetuity. It is made available under aCC-BY 4.0 International license.

\section{Phase-based cortical synchrony is affected by prematurity}

154 networks at limited oscillatory frequencies.

\section{PPC networks are affected by prematurity in a frequency-specific manner}

We found broad sleep- and frequency- specific differences in PPC networks between EP and HC infants (Figure 2). During AS, the most extensive group differences were observed within the theta frequency band (peak at $\mathrm{Fc}=5.3 \mathrm{~Hz}$; Figure 2a) with stronger connections in the EP group $(K=10 \%, p<0.01, q=0.01)$ that were uniformly distributed over the whole cortex (Figure $2 \mathrm{~b})$ and preferentially long-range. Smaller subnetworks $(K=2-4 \%, p<0.01, q=0.01)$ of both increased and decreased connectivity in EP infants were at delta frequencies (1.8-3.1 $\mathrm{Hz}$ ) covering central and temporal regions. During QS, the most prominent group differences were within the delta band: The EP infants exhibited stronger connectivity $(K=10 \%$ at $1.8 \mathrm{~Hz}$, $p<0.01, q=0.01)$ in mostly long-range connections between frontal and occipital lobes, while there were weaker short-range connections $(K=8 \%$ at $1.2 \mathrm{~Hz}, p<0.01, q=0.01)$ within the frontal lobe and a few projections to the parietal lobe. Networks at alpha and beta frequencies were suppressed in the EP infants during both sleep states, and they mainly involved basal connections linking occipital cortices to frontal and temporal areas.

No significant correlations (Spearman, two-tailed test, $\alpha=0.05$, Benjamini-Hochberg correction) were found between mean connectivity strength and age per frequency. Effect sizes, computed by the rank-biserial correlation over each significant network, are presented in Figure 2-figure supplement 1. The spatial differences in PPC networks between groups for all frequency bands are shown at Figure 2-figure supplement 2. We also validated the results with an alternative analysis using network-based statistics (NBS), (Zalesky et al., 2010), with two one-tailed tests (for details, see Methods), and we found strikingly similar spectral and spatial patterns in group comparisons (Figure 2-figure supplement 3). The findings together suggest that exposure to prematurity affects the organization of cortical PPC 


\section{Phase-based cortical synchrony is affected by prematurity}

a

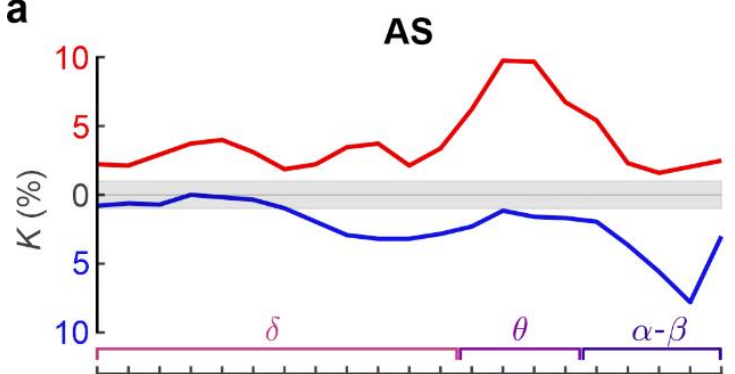

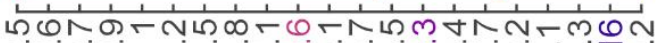

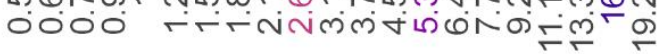

b
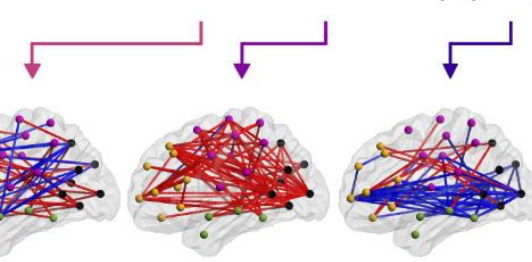

180

181

182

183

184

185

186

187

188

189

190

191

192

193

194

195

196

197 of the networks (red, blue) is equal to that of (a).

Figure 2. Effects of prematurity on cortical PPC networks. (a) Network density $(K)$ of significant PPC group differences (two one-tailed Wilcoxon rank-sum tests, $\alpha=0.01$ ) during active sleep (AS, left) and quiet sleep (QS, right) as a function of frequency. Networks that are stronger in EP $(E P>\mathrm{HC})$ are shown in red, whereas networks with suppressed connectivity in EP $(E P<H C)$ are presented in blue. The grey shaded area depicts the boundaries of the $q$-level showing the potential level of false discoveries $(q=0.01)$. The data presented in the figure is provided in Figure 2-source data 1 and matrices of the $p$-values and effect sizes of all networks in Figure 2-source data 2. (b) Spatial visualizations present PPC network comparisons at the frequencies with the most extensive group differences. The color coding

\section{Connectivity strength correlates with neurological performance in preterm infants}

Next, we studied how the strength of cortical PPC networks correlates to neurological performance at the time of newborn EEG recordings. To this end, we correlated the connectivity strengths of each PPC network connection $(N=1128)$ of the EP group to the neurological performance of the corresponding infants, assessed using compound scores C1 


\section{Phase-based cortical synchrony is affected by prematurity}

and C2, which are associated with later motor and cognitive outcomes, respectively (Tokariev et al., 2019b). We estimated the fraction of significantly correlated connections using a density measure $(K)$ across the whole frequency domain, and visualized the networks showing broad spatial effects (Figure 3).

The C2 score was positively correlated with an extensive pattern at higher delta frequencies in both sleep states (AS: $1.2-4.5 \mathrm{~Hz}, K=5-14 \%$, QS: 1.2-3.1 Hz, $K=6-10 \%, p<0.05, q=$ 0.05). The corresponding spatial patterns incorporated broad networks linking multiple distal areas. In contrast, the $\mathrm{C} 1$ score showed only mildly elevated density, or small networks, with positive correlation at 2.6-4.5 Hz during AS $(K=4-8 \%, p<0.05, q=0.05)$, and a negative correlation at $1.5-1.8 \mathrm{~Hz}$ during $\mathrm{QS}(K=5-6 \%, p<0.05, q=0.05)$. Effect sizes (mean of Spearman $\rho$ over the positive and negative correlation networks) are depicted in Figure 3figure supplement 1. A comparable analysis for healthy controls (Figure 3-figure supplement 2) showed only a few negative correlations between edge strength and neurological scores. The spatial distributions for all investigated frequency bands are presented in Figure 3-figure supplement 3 for $\mathrm{C} 1$ and Figure 3-figure supplement 4 for $\mathrm{C} 2$.

These findings together suggest that the relationship between cortical networks and neurological performance is affected by prematurity. The EP infants exhibit brain-wide relationships between cortical networks and neurological performance, which is not seen in the $\mathrm{HC}$ infants. 
C1
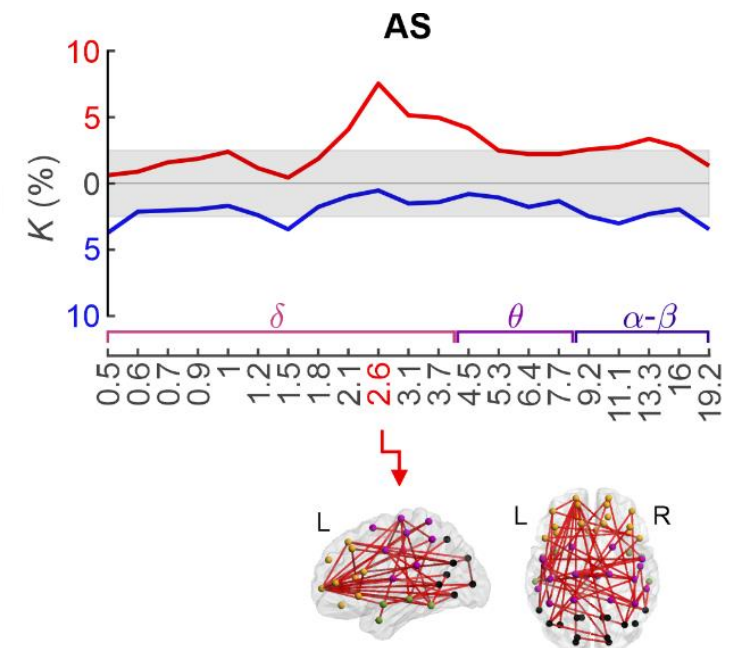

C2
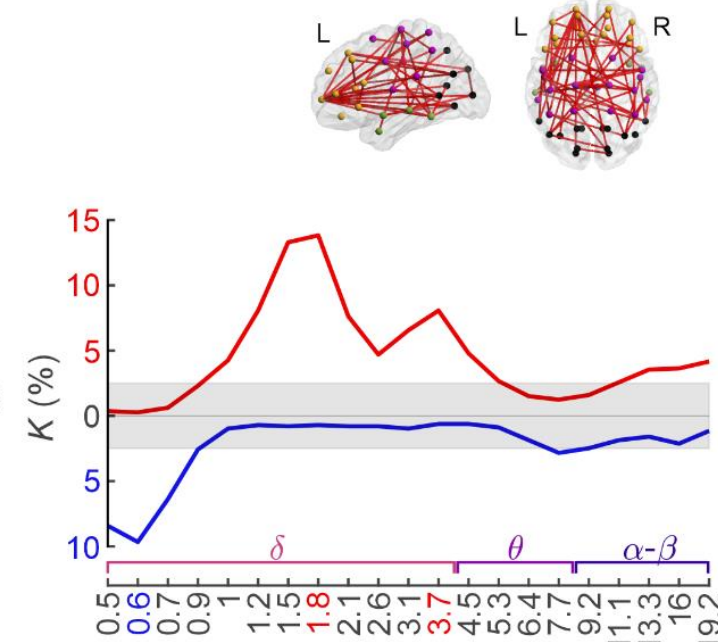
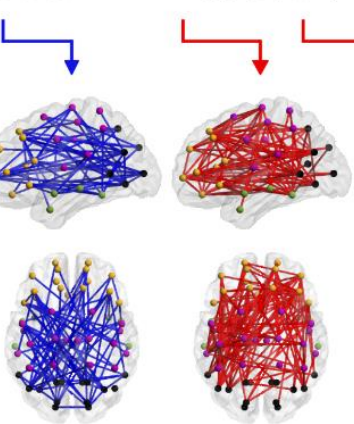
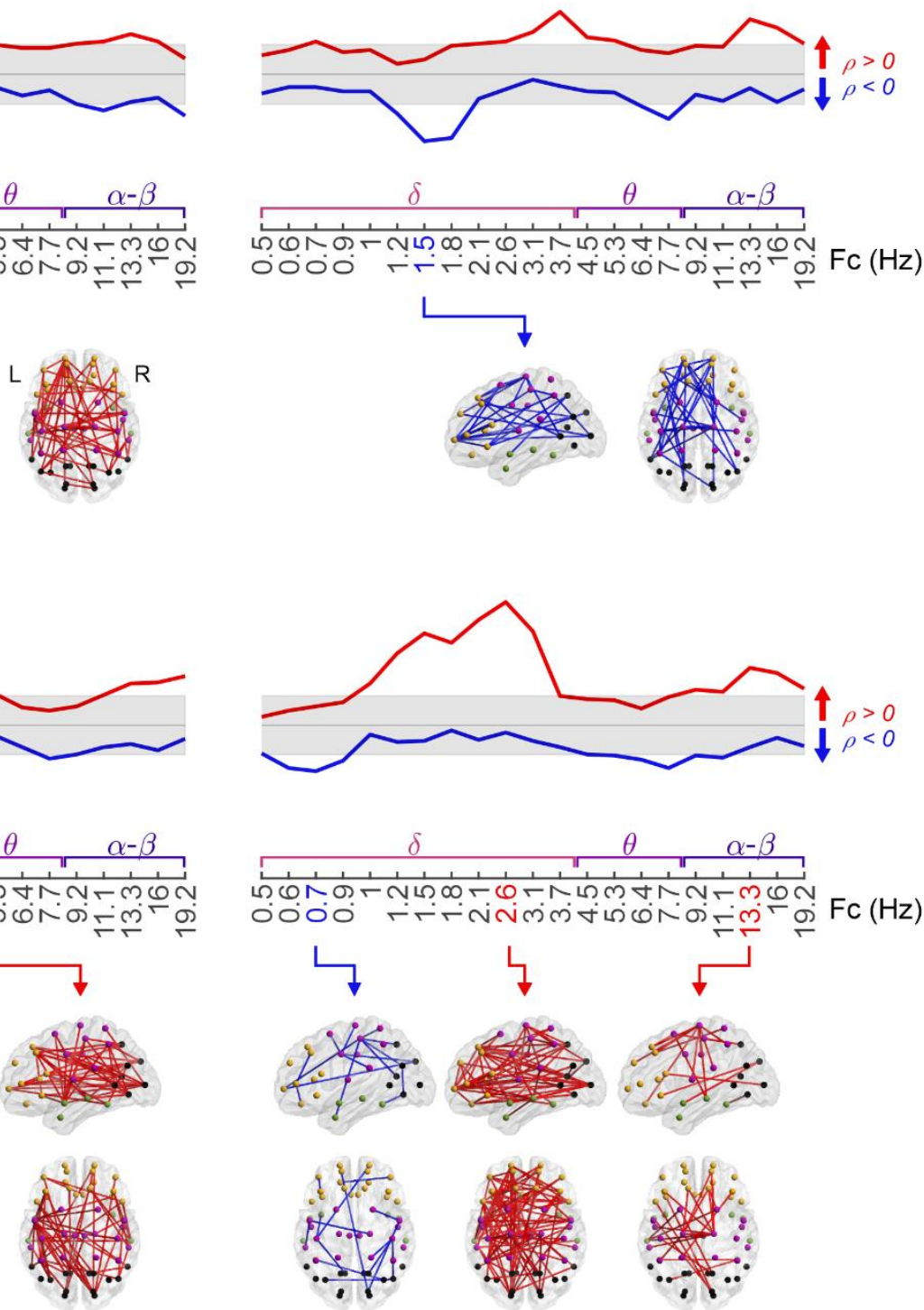

Figure 3. PPC networks of ex-preterm infants at term age predict neurological outcome.

Density ( $K$ ) of PPC patterns that associate to neurological scores C1 and C2 (Spearman, two-

tailed test with conceptional age as a covariate, $\alpha=0.05$ ) as a function of frequency. The grey

shaded area depicts the FDR boundaries $(q=0.05)$. The opaque brains show the spatial distributions of networks taken at the most characteristic peaks of the density curves. Red coloring pictures networks with positive correlation $(\rho \geq 0)$, while blue coloring shows negatively correlated connections $(\rho<0)$ in both the graphs and 3-dimensional plots. The graph data is provided in Figure 3-source data 1 and the full $p$-value and effect size matrices in Figure 3-source data 2. 
233 Correlation of functional connectivity and neurological performance extends to long-

\section{4 term neurocognitive outcomes}

235 Finally, we examined the relation of PPC networks to long-term neurocognitive development, assessed at 2 years of age using standardized Bayley (Bayley, 2006) and Griffiths (Huntley, 1996) scores. Akin to our analysis above on newborn clinical performance, we also correlated the strength of individual connections in the PPC networks of the EP infants to their clinical outcome measures at two years of age. Most of the significant correlations emerged for visual, motor, cognitive, and language comprehension scores at lower frequencies (Figure 4), forming mostly spatially constrained patterns.

242

243 Visual scores correlated positively with PPC at Fc $=0.5 \mathrm{~Hz}$ during both sleep states $(K=5-$ $6 \%, p<0.05, q=0.05)$, involving networks from left frontal and right occipital regions. There were also some negative correlations between visual scores and PPC during AS $(K=6-8 \%$, $p<0.05, q=0.05)$, located mostly in the frontal regions $(\mathrm{Fc}=2.6 \mathrm{~Hz})$ or occipital regions $(\mathrm{Fc}$ $247=7.7 \mathrm{~Hz})$.

Motor scores featured a prominent positive correlation during both sleep states at $\mathrm{Fc}=1.5 \mathrm{~Hz}$ $(K=7 \%, p<0.05, q=0.05)$ with a broad spatial distribution over several cortical regions. We also found a somewhat smaller extent network with a positive correlation to motor score during QS at a slightly higher frequency $(\mathrm{Fc}=3.1 \mathrm{~Hz} ; K=5 \%, p<0.05, q=0.05)$. Finally, a subset of occipital interhemispheric connections showed negative correlation to motor scores during both sleep states at the lowest frequencies ( $\mathrm{Fc}=0.6 \mathrm{~Hz} ; K=4 \%, p<0.05, q=0.05)$. 


\section{Phase-based cortical synchrony is affected by prematurity}

259

260

261

262

263

264

265

266

267

268

269

270

271

272

273

274

275

276

277

278

279

smaller network displayed positive correlations with cognitive performance during AS at Fc = $1.8 \mathrm{~Hz}(K=4 \%, p<0.05, q=0.05)$, involving mostly frontal connections.

Language comprehension was strongly and positively correlated to PPC strength in AS (peak at $\mathrm{Fc}=1.8 \mathrm{~Hz}, K=5 \%, p<0.05, q=0.05)$, involving networks from the left temporal to frontal regions, aligning well with the cortical areas that are known to participate in language comprehension (Tremblay \& Dick, 2016). A negative correlation between PPC strength and language comprehension scores was present during QS in the basal long-range connections at lower frequencies $(\mathrm{Fc}=0.5 \mathrm{~Hz}, K=5 \%, p<0.05, q=0.05)$, as well as diffuse brain-wide network at mid-frequencies during $\mathrm{AS}(\mathrm{Fc}=7.7 \mathrm{~Hz}, K=4 \%, p<0.05, q=0.05)$.

Effect sizes were computed as the mean of Spearman $\rho$ of the positive and negative networks separately and are presented as a function of frequency in Figure 4-figure supplement 1. The spatial distributions at all investigated frequency ranges are shown in Figure 4-figure supplement $2-5$.

(1) 

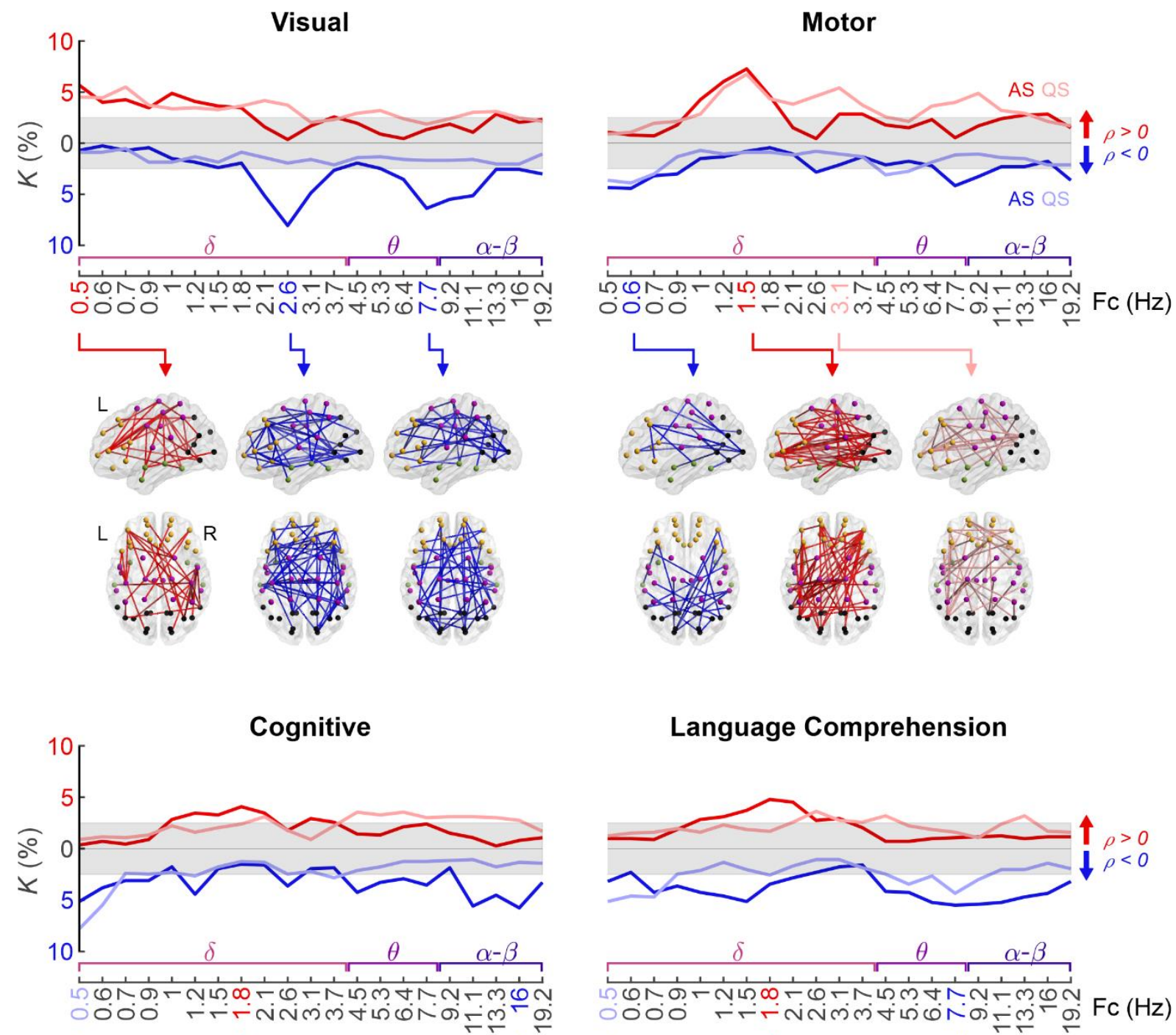

\section{Language Comprehension}

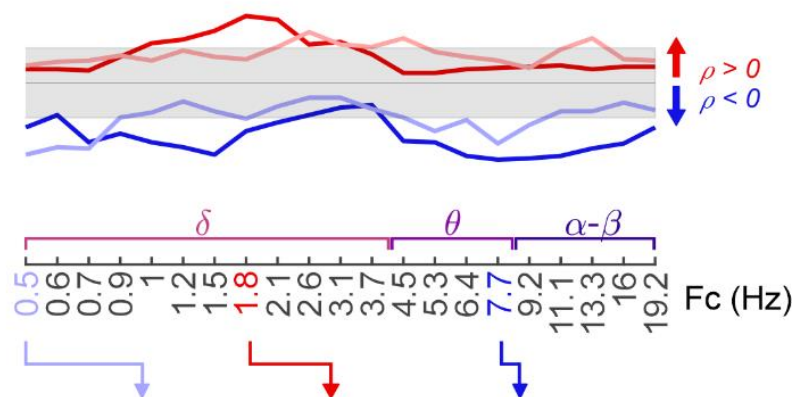

Figure 4. Correlation of PPC network strength to 2-year neurocognition. The upper graphs show the frequency-wise summary of the proportion of network edges $(K)$ that show a significant correlation between PPC strength and the given neurocognitive performance score (Spearman, two-tailed test with conceptional age as a covariate, $\alpha=0.05)$. The FDR $(q=0.05)$ boundaries are depicted as a grey shaded area. The strongest peaks in these plots were 
bioRxiv preprint doi: https://doi org/10.1101/2021.02.15.431226 this version posted February 18, 2021. The copyright holder for this preprint (which was not certified by peer review) is the author/funder, who has granted bioRxiv a license to display the preprint in perpetuity. It is made available under aCC-BY 4.0 International license.

Phase-based cortical synchrony is affected by prematurity

287 selected for the 3-dimensional visualisations of networks as indicated with arrows. Colour

288 coding represents the sign of correlation (red: $\rho \geq 0$, blue $\rho<0$ ) and hues represent sleep

289 states (dark: AS, light: QS) in the graphs and the spatial visualisations. The data displayed in

290 the curves is provided in Figure 4-source data 1 and the $p$-value and effect size matrices

291 from which the graphs were created in Figure 4-source data 2. 
bioRxiv preprint doi: https:/doi.org/10.1101/2021.02.15.431226; this version posted February 18, 2021. The copyright holder for this preprint (which was not certified by peer review) is the author/funder, who has granted bioRxiv a license to display the preprint in perpetuity. It is made available under aCC-BY 4.0 International license.

Phase-based cortical synchrony is affected by prematurity

\section{Discussion}

293 Our study shows that spontaneous cortical activity in the human infants exhibits large-scale 294 PPC structures, that are spectrally and spatially selective and co-vary with vigilance states. Moreover, we show that the globally most significant clinical risk factor, preterm birth (WHO, 2012), leads to frequency-selective changes in these networks, which correlate to neurocognitive performance of the affected individuals. Our work employed novel realistic cortical source reconstruction and independent parallel analyses to validate the results on clinical network correlations. Our findings are broadly consistent with recent work on adults showing that multiple frequency-specific PPC networks coexist (De Domenico et al., 2016; Siebenhühner et al., 2016; Vidaurre et al., 2018; Yu et al., 2017) and correlate with normal and pathological behaviour (Siebenhühner et al., 2016; Yu et al., 2017). Our work extends prior studies reporting prematurity effects on the temporally loose amplitude correlations (Omidvarnia et al., 2014; Tokariev et al., 2019a); here we provide evidence that the corticocortical interactions in newborn infants are already accurate enough to give rise to spectrally and spatially specific PPC structures, and pathological effects therein.

It has recently become clear that brain function relies on several co-existing frequency-specific PPC networks, which are reported to show temporal dynamics between awake states in the adults (Siebenhühner et al., 2016; Vidaurre et al., 2018) or between sleep states in the neonatal studies (Tokariev et al., 2019b; Tokariev et al., 2016b). Here, we show that medical adversities can affect these PPC networks in a selective manner, at preferential frequencies,

313 and with preferential spatial distributions, as well as differing between vigilance states. For

314 instance, prematurity caused an increase in middle frequency PPC in long-range connections

315 throughout the brain, while the changes in higher frequencies were more localized in the middle and long-range connections in the basal brain areas. These effects were more pronounced during active sleep for the middle frequencies, while high frequency findings were 
bioRxiv preprint doi: https://doi org/10.1101/2021.02 15.431226; this version posted February 18,2021 . The copyright holder for this preprint (which was not certified by peer review) is the author/funder, who has granted bioRxiv a license to display the preprint in perpetuity. It is made available under aCC-BY 4.0 International license.

\section{Phase-based cortical synchrony is affected by prematurity}

319 functional significance of frequency-specific PPC networks depends on their context, the brain 320 state, in addition to their given frequency.

321

322 Our present findings extend the long-held clinical tradition where quiet sleep is considered to be the most sensitive state in disclosing effects of prematurity in the EEG records. In the clinical visual review, the EEG signal is considered to exhibit dysmature/immature features (Lombroso, 1979; Tharp, 1990), and the most robust feature is augmented "interhemispheric asynchrony", or temporal non-overlap between cortical bursting (Koolen et al., 2014; Räsänen et al., 2013). While the clinically perceived interhemispheric asynchrony considers quiet sleep and amplitude correlations only, here we show that robust prematurity effects are also seen in the PPC networks, and they are clear during active sleep. Moreover, the functional significance of the PPC network during active sleep is shown by their pronounced correlations to subject-level clinical performance.

333 The strength of PPC connectivity in several brain-wide subnetworks was found to correlate to 334 infants' neurological performance at term age, which extends prior reports on clinical correlations to frontally connected delta frequency networks (Tokariev et al., 2019b). Clinical correlations were clearly widest for the C2 composite score which emphasizes features of newborn performance that pre-empt later cognitive development (Tokariev et al., 2019b).

338 Comparison to neurocognitive performance at 2 years of age showed also several albeit smaller PPC subnetworks with significant correlations. PPC connectivity relies on a temporally accurate neural communication that requires sufficiently matured cortico-cortical pathways

341 (Palva \& Palva, 2011; Womelsdorf et al., 2007). The previously described diffuse and 342 extensive white matter abnormalities after prematurity (Dimitrova et al., 2020) may provide a 343 straightforward histological underpinning for the changes, especially the observed decrease in higher frequency PPC networks. 
bioRxiv preprint doi: https:/doi org/10.1101/2021.02 15.431226; this version posted February 18, 2021. The copyright holder for this preprint (which was not certified by peer review) is the author/funder, who has granted bioRxiv a license to display the preprint in perpetuity. It is made available under aCC-BY 4.0 International license.

Phase-based cortical synchrony is affected by prematurity

346 While our findings suggest clinically meaningful functions for the herein characterized PPC

347 networks in the EP infants, it was somewhat unexpected that comparable correlations were

348 not found in the group of healthy control infants. That observation suggests an altered

349 relationship between PPC networks and neurocognitive phenotypes, which calls for a reasonable mechanistic explanation. It is possible that the network-phenotype relationship becomes amplified in the preterm cohort that is known to exhibit considerable variation in their histological maturation (Dimitrova et al., 2020). Prior studies have shown brain-wide effects of prematurity on the histological structures of white matter tracts (Dimitrova et al., 2020) and these changes were shown to correlate with several characteristics of newborn or later neurocognitive performance (Girault et al., 2019; Stjerna et al., 2015; Toulmin et al., 2020; Vollmer et al., 2017). An alternative mechanism is that the effects found in EP infants reflect a transient network immaturity (Lombroso, 1979; Tharp, 1990) that would catch up during later development. Testing this hypothesis would need repeated EEG network studies in the EP infants near term-equivalent age to show a developmental catch up in the PPC networks (Tokariev et al., 2016b) or in other functional brain age (Stevenson et al., 2020).

The present results suggest a clinically meaningful effect on PPC networks that could potentially serve as a functional biomarker to, e.g., benchmark early therapeutic interventions (Ewen et al., 2019; Sahin et al., 2020). Our current study needs to be considered as observational work that identified putative analysis pipelines and network markers. Future prospective studies on larger cohorts are needed for their validation, and to define the perceived added value of network assessment from the perspective of monitoring early neurodevelopment and benchmarking early therapeutic interventions. In addition, the hereby demonstrated network effects may offer a unique translational bridge: The PPC networks could be used as a functional benchmark for establishing the clinical neurodevelopmental relevance of preclinical models of human prematurity. 


\section{Methods}

373 The full study pipeline can be viewed in Figure 1.

\section{Subjects}

376 The dataset included $\mathrm{N}=46$ early preterm $(\mathrm{EP})$ and $\mathrm{N}=67$ healthy control $(\mathrm{HC})$ infants. The

377 conceptional ages (CA) at birth of the EP group (mean \pm standard deviation, SD) were 24.4

$378 \pm 1.2$ weeks and those of the $\mathrm{HC}$ group were $38.4 \pm 1.1$ weeks. This dataset was collated from cohorts that have been published in previous studies (Omidvarnia et al., 2014; Tokariev et al., 2016b; Tokariev et al., 2019a; Tokariev et al., 2019b). The study design was approved by the Ethics Committee of the Helsinki University Central Hospital and informed consent was obtained from a parent or guardian for each subject.

383

\section{EEG recordings}

Multi-channel scalp EEG data was collected from both infant groups during day sleep. The requirement for the recording session was that each subject had to undergo two vigilance states: active sleep (AS) and quiet sleep (QS). EEG registration was performed using Waveguard caps with 19-28 sintered $\mathrm{Ag} / \mathrm{AgCl}$ electrodes (ANT-Neuro, Berlin, Germany) located according to International 10-20 standard layout. Signals from both groups were recorded mostly with the NicOne EEG amplifier (Cardinal Healthcare, Ohio/Natus, Pleasanton, USA), but few EP subjects were recorded with the Cognitrace amplifier (ANT Data Format (EDF). 
bioRxiv preprint doi: https://doi org/10.1101/2021.02 15.431226; this version posted February 18,2021 . The copyright holder for this preprint (which was not certified by peer review) is the author/funder, who has granted bioRxiv a license to display the preprint in perpetuity. It is made available under aCC-BY 4.0 International license.

\section{Phase-based cortical synchrony is affected by prematurity}

398

Newborn neurological assessments (Hammersmith Neonatal Neurological Examination (HNNE), (Dubowitz et al., 1999), were conducted on the EP and HC cohorts at term-equivalent age. The test comprises six separate domains of neurodevelopment: reflexes, movements, posture tonus, tone patterns, abnormal signs, orientation and behaviour. To render them suitable for studying associations with PPC networks, we used dimensionality reduction as described earlier (Tokariev et al., 2019b). In brief, we created combination scores, C1 and C2, using principal component analysis (PCA) with Varimax Rotation from three individual tests (visual alertness, head raising in prone, and increased neck extensor tone). In the post hoc assessment, the resulting $\mathrm{C} 1$ was shown to correlate primarily with later motor performance, whereas C2 was found to be associated with later cognitive and social performance (Tokariev et al., 2019b).

Long-term neurocognitive follow-up assessment was performed only on the EP infants at two years of age, using Bayley Scales of Infant and Toddler Development (Bayley, 2006) and the Griffiths Mental Developmental Scales (Huntley, 1996). The neuropsychological follow-up data was not available for the HC infants. These neurocognitive assessment tests were chosen, because of their established, widespread clinical use plus a broad impact on lifelong neurocognitive performance and quality of life, hence supporting the translational potential of findings (Hernandez, 2018; Rogers \& Hintz, 2016). While some other outcomes such as gross motor development or hearing may be sometimes affected in EP infants, prior studies have suggested that these are most likely modified by a host of individual and treatment interventions (Kilbride et al., 2018).

\section{EEG review and pre-processing}

Vigilance state assessment was performed through a combination of electrophysiological and behavioral measures, the latter observed using polygraphic channels (chin electromyogram, electrocardiogram, electrooculogram, and respiratory sensors). EEG traces during AS exhibit 
bioRxiv preprint doi: https:/doi org/10.1101/2021.02.15.431226; this version posted February 18, 2021. The copyright holder for this preprint (which was not certified by peer review) is the author/funder, who has granted bioRxiv a license to display the preprint in perpetuity. It is made available under aCC-BY 4.0 International license.

\section{Phase-based cortical synchrony is affected by prematurity}

425

426

427

428

429

430

431

432

433

434

435

436

437

438

439

440

441

442

443

444

445

446

\section{Computation of cortical signals}

448 Band-pass filtered EEG were further source reconstructed to allow better spatial separation of

continuous fluctuations, with an irregular respiration and occasional eye movements. Conversely, EEG during QS is characteristically discontinuous, with a regular respiration (André et al., 2010). We then selected 5-min-long artifact-free EEG epochs from representative periods of AS and QS. To avoid transition periods between vigilance states, representative sleep epochs were selected from within well-established patterns of corresponding behavior and brain activity. Epochs that did not meet quality and length requirements were excluded from the data pool. As a result, we obtained four final groups: EP-AS $(N=46)$, HC-AS $(N=53)$, EP-QS $(N=42)$, and HC-QS $(N=66)$. For each subject we selected the same $\mathrm{N}=19$ channels (Fp1, Fp2, F7, F3, Fz, F4, F8, T7, C3, Cz, C4, T8, P7, P3, $\mathrm{Pz}, \mathrm{P} 4, \mathrm{P} 8, \mathrm{O} 1, \mathrm{O} 2)$ to enable group-level analysis. All EEG signals were first pre-filtered within the $0.15-45 \mathrm{~Hz}$ frequency range using a combination of high- and low-pass Butterworth filters of the 7th order. All filtering in this work were implemented offline and in forward-backward directions to compensate for phase delays introduced by infinite impulse response filters. Next, the EEG data were downsampled to a new sampling frequency, $\mathrm{Fs}=100 \mathrm{~Hz}$, and converted into average montage. Following our previous work (Tokariev et al., 2019a), we filtered the pre-processed EEG into 21 frequency bands of interest covering the range $0.4-22 \mathrm{~Hz}$. Bandpass filtering was also implemented with pairs of low- and high-pass filters. The first central frequency $(\mathrm{Fc})$ was set to $0.5 \mathrm{~Hz}$ and subsequent frequencies were computed as $\mathrm{Fc}(\mathrm{i})=$ $1.2 \times \mathrm{Fc}(\mathrm{i}-1)$, where $\mathrm{i}$ is the number of the frequency band. Cut-off frequencies for each band were taken as $0.85 \times \mathrm{Fc}$ and $1.15 \times \mathrm{Fc}$ correspondingly. This approach leads to $50 \%$ overlapping frequency bands of semi-equal width in the logarithmic scale.

cortical activities using a realistic infant head model (Tokariev et al., 2019b) and dynamic statistical parametric mapping (Dale et al., 2000). As the source space we used normal to cortical surface (at term age) dipoles of fixed orientation $(\mathrm{N}=8014)$. The scalp and inner/outer 
bioRxiv preprint doi: https://doi org/10.1101/2021.02 15.431226; this version posted February 18,2021 . The copyright holder for this preprint (which was not certified by peer review) is the author/funder, who has granted bioRxiv a license to display the preprint in perpetuity. It is made available under aCC-BY 4.0 International license.

\section{Phase-based cortical synchrony is affected by prematurity}

452

skull shells were segmented from magnetic resonance imaging (MRI) data from healthy fullterm infant. Following previous studies (Despotovic et al., 2013; Odabaee et al., 2014; Tokariev et al., 2016a), tissue conductivities were set to: $0.43 \mathrm{~S} / \mathrm{m}$ for scalp, $1.79 \mathrm{~S} / \mathrm{m}$ for intracranial volume, and $0.2 \mathrm{~S} / \mathrm{m}$ for skull. Finally, cortical sources were clustered into $\mathrm{N}=58$ parcels according to the scheme optimized for infant EEG. Cortical signals representing neural activity of each parcel were computed as the weighted mean of source signals belonging to the host parcels (Tokariev et al., 2019b).

\section{Computation of functional connectivity}

To estimate functional connectivity, we computed phase-phase correlations (PPC) between all pairs of parcels using the debiased weighted phase-lag index (dwPLI), (Vinck et al., 2011). We opted to use this metric because of its robustness to artificial interactions caused by volume conduction (Palva et al., 2018; Palva \& Palva, 2012). Connectivity was estimated using whole 5-min-long epochs, at 21 frequency bands and for both vigilance states (AS and QS). This led to a set of $58 \times 58$ PPC matrices for each subject. Next, we corrected these matrices by multiplication with a binary 'fidelity' mask, which was computed for the particular electrode layout. This mask was generated using extensive simulations based on the head model, and it removes 'noisy' connections from a connectivity matrix (Tokariev et al., 2019b). This procedure aims to improve the reliability of cortical-level network estimation from a suboptimal number of recording electrodes which are usually used in clinical recordings (Tokariev et al., 2016a). Note, that fidelity mask removes the same edges from all empirical connectivity matrices.

\section{Network analysis}

To test network differences between EP and HC, we applied the Wilcoxon rank sum test (two one-tailed tests, $\alpha=0.01$ ) in an edge-by-edge manner with defined directions (EP $>\mathrm{HC}$ and $E P<H C)$. This was done for each frequency band and for each sleep state separately. As a result of such edgewise scanning, we obtained matrices of $p$-values corresponding to the 
bioRxiv preprint doi: https:/doi org/10.1101/2021.02 15.431226; this version posted February 18, 2021. The copyright holder for this preprint (which was not certified by peer review) is the author/funder, who has granted bioRxiv a license to display the preprint in perpetuity. It is made available under aCC-BY 4.0 International license.

\section{Phase-based cortical synchrony is affected by prematurity}

network connections and computed the ratio $(K)$ of edges with significant group difference to the full network. To estimate the potential number of false discoveries in the frequency-specific group contrasts, we employed the Storey-Tibshirani adaptive FDR method using $q=0.01$ with respect to the size of the whole network (i.e., up to $\mathrm{N}=1128 \times 0.01=11$ connections in each network were classified as potential false discoveries), (Puoliväli et al., 2020; Storey \& Tibshirani, 2003). Effect size for the significantly different patterns was computed as a module of the mean of rank-biserial correlation values for corresponding connections. The influence of age differences on network strength was investigated by correlating the global mean connectivity strength with age for each group per frequency and sleep state (Spearman correlation, two-tailed test, $\alpha$-level 0.05$)$. The $p$-values of both sleep states were pooled together separately for each group and controlled for multiple comparisons by the BenjaminiHochberg procedure (Benjamini \& Hochberg, 1995).

Parallel to the primary analysis, a cross-check for statistical group comparison was performed using network-based statistics (NBS) (Zalesky et al., 2010) separately for the 21 frequency bands and two sleep states using two one-tailed tests (EP $>\mathrm{HC}$ and $\mathrm{EP}<\mathrm{HC}$ ). NBS is a multiple comparisons method designed specifically for network analysis. It assumes that connections reflecting true effects are interconnected into networks encompassing more than a single connection. The connected components are defined in a topological space, in contrary to other cluster-based methods, which use a physical space (Genovese et al., 2002; Zalesky et al., 2010). The initial threshold for the t-statistic was set to 2.5 , followed by the post hoc permutation test to correct the family-wise error rate (5000 permutations, $\alpha=0.05$ ).

\section{Clinical correlation}

The connectivity strength of each edge across the infant group was correlated with the corresponding neurological assessments at term-equivalent age and with the corresponding neurocognitive performance scores at two years of age (Spearman, two-tailed test with $\alpha$-level 0.05) with conceptional age as a covariate. We computed the fraction of edges showing 


\section{Phase-based cortical synchrony is affected by prematurity}

508

509

510

511

512

513

514

515

516

517

518

519

520

521

522

523

524

525

526

527

528 The Matlab script implementing the network analyses of group differences and clinical 529 correlation can be found at https://github.com/pauliina-yrjola/Preterm-Phase.

significant clinical correlation $(K)$ for each frequency band and sleep state. Only the EP cohort had performance scores tested at 2 years of age. Some subjects had missing clinical scores, rendering the number of subjects used for each correlation to: C1: EP-AS ( $=39)$, EP-QS (N $=36), \mathrm{HC}-\mathrm{AS}(\mathrm{N}=30)$, HC-QS $(\mathrm{N}=51)$; C2: EP-AS $(\mathrm{N}=39)$, EP-QS $(\mathrm{N}=36), \mathrm{HC}-\mathrm{AS}(\mathrm{N}=$ 40), HC-QS ( $=51)$; Griffiths Visual: EP-AS ( $N=35)$, EP-QS ( $=32)$; Griffiths Motor: EPAS ( $N=39)$, EP-QS $(N=36)$; Bayley Cognitive: EP-AS $(N=32)$, EP-QS $(N=30)$; Bayley Language comprehension: EP-AS $(\mathrm{N}=30)$, EP-QS $(\mathrm{N}=28)$. Multiple comparisons correction was implemented with the Storey-Tibshirani adaptive FDR with $q=0.05$ (i.e., $2.5 \%$ of the positive and negative correlations separately were classified as potential false discoveries). The Spearman $\rho$-value was used for estimating effect size: it was computed for all significant edges and averaged across the full network.

\section{Analysis software}

Source reconstruction was conducted using the Brainstorm (Tadel et al., 2011), (https://neuroimage.usc.edu/brainstorm/Introduction), and the openMEEG (Gramfort et al., 2010), (https://openmeeg.github.io/), software packages. Analyses were performed with Matlab R2020a (MathWorks, Naticks, MA, USA) and NBS Connectome (Zalesky et al., 2010), (https://www.nitrc.org/projects/nbs/), and the visualization of brain networks was carried out with BrainNet Viewer (Xia et al., 2013), (https://www.nitrc.org/projects/bnv/). correlation can be found at htps:/github.com/paulina-yiola/Preterm-Phase. 
bioRxiv preprint doi: https://doi. org/10.1101/2021.02.15.431226. this version posted February 18, 2021. The copyright holder for this preprint (which was not certified by peer review) is the author/funder, who has granted bioRxiv a license to display the preprint in perpetuity. It is made available under aCC-BY 4.0 International license.

Phase-based cortical synchrony is affected by prematurity

\section{Bibliography}

532

533

534

535

536

537

538

539

540

541

542

543

544

545

546

547

548

549

550

551

552

553

554

555

556

557

558

559

560

561

562

André, M., Lamblin, M.-D., d’Allest, A.-M., Curzi-Dascalova, L., Moussalli-Salefranque, F., Tich, S. N. T., Vecchierini-Blineau, M.-F., Wallois, F., Walls-Esquivel, E., \& Plouin, P. (2010). Electroencephalography in premature and full-term infants. Developmental features and glossary. Neurophysiologie Clinique/Clinical Neurophysiology, 40(2), 59-124.

Batalle, D., Hughes, E. J., Zhang, H., Tournier, J.-D., Tusor, N., Aljabar, P., Wali, L., Alexander, D. C., Hajnal, J. V., \& Nosarti, C. (2017). Early development of structural networks and the impact of prematurity on brain connectivity. Neuroimage, 149, 379-392.

Bayley, N. (2006). Bayley scales of infant and toddler development, San Antonio, TX: Harcourt Assessment. Inc. p, 266.

Benjamini, Y., \& Hochberg, Y. (1995). Controlling the false discovery rate: A practical and powerful approach to multiple testing. Journal of the Royal Statistical Society: Series B (Methodological), 57(1), 289-300.

Bressler, S., \& Menon, V. (2010). Large-scale brain networks in cognition: Emerging methods and principles. Trends in Cognitive Sciences, 14(6), 277-290.

Dale, A., Liu, A. K., Fischl, B. R., Buckner, R. L., Belliveau, J. W., Lewine, J. D., \& Halgren, E. (2000). Dynamic statistical parametric mapping: Combining fMRI and MEG for high-resolution imaging of cortical activity. Neuron, 26(1), 55-67.

De Domenico, M., Granell, C., Porter, M. A., \& Arenas, A. (2016). The physics of spreading processes in multilayer networks. Nature Physics, 12(10), 901-906.

Despotovic, I., Cherian, P. J., De Vos, M., Hallez, H., Deburchgraeve, W., Govaert, P., Lequin, M., Visser, G. H., Swarte, R. M., \& Vansteenkiste, E. (2013). Relationship of EEG sources of neonatal seizures to acute perinatal brain lesions seen on MRI: A pilot study. Human Brain Mapping, 34(10), 2402-2417.

Dimitrova, R., Pietsch, M., Christiaens, D., Ciarrusta, J., Wolfers, T., Batalle, D., Hughes, E., Hutter, J., CorderoGrande, L., \& Price, A. N. (2020). Heterogeneity in brain microstructural development following preterm birth. Cerebral Cortex, 30(9), 4800-4810.

Dubowitz, L., Dubowitz, V., \& Mercuri, E. (1999). The neurological assessment of the preterm and full-term newborn infant. Cambridge University Press.

Engel, A., Gerloff, C., Hilgetag, C. C., \& Nolte, G. (2013). Intrinsic coupling modes: Multiscale interactions in ongoing brain activity. Neuron, 80(4), 867-886.

Ewen, J., Sweeney, J. A., \& Potter, W. Z. (2019). Conceptual, regulatory and strategic imperatives in the early days of EEG-based biomarker validation for neurodevelopmental disabilities. Frontiers in Integrative Neuroscience, 13, 45. 
bioRxiv preprint doi: https://doi.org/10.1101/2021.02 15.431226. this version posted February 18, 2021. The copyright holder for this preprint (which was not certified by peer review) is the author/funder, who has granted bioRxiv a license to display the preprint in perpetuity. It is made available under aCC-BY 4.0 International license.

\section{Phase-based cortical synchrony is affected by prematurity}

Genovese, C., Lazar, N. A., \& Nichols, T. (2002). Thresholding of Statistical Maps in Functional Neuroimaging Using the False Discovery Rate. Neurolmage, 15(4), 870-878. https://doi.org/10.1006/nimg.2001.1037

Girault, J., Cornea, E., Goldman, B. D., Knickmeyer, R. C., Styner, M., \& Gilmore, J. H. (2019). White matter microstructural development and cognitive ability in the first 2 years of life. Human Brain Mapping, 4O(4), $1195-1210$.

Gramfort, A., Papadopoulo, T., Olivi, E., \& Clerc, M. (2010). OpenMEEG: Opensource software for quasistatic bioelectromagnetics. Biomedical Engineering Online, 9(1), 1-20.

Guo, T., Duerden, E. G., Adams, E., Chau, V., Branson, H. M., Chakravarty, M. M., Poskitt, K. J., Synnes, A., Grunau, R. E., \& Miller, S. P. (2017). Quantitative assessment of white matter injury in preterm neonates: Association with outcomes. Neurology, 88(7), 614-622.

Hipp, J., Hawellek, D. J., Corbetta, M., Siegel, M., \& Engel, A. K. (2012). Large-scale cortical correlation structure of spontaneous oscillatory activity. Nature Neuroscience, 15(6), 884-890.

Huntley, M. (1996). The Griffiths mental developmental scales manual from birth to two years. Association for the Research in Infant and Child Development (The Test Agency, Thames, 1996).

Johnson, S., \& Marlow, N. (2017). Early and long-term outcome of infants born extremely preterm. Archives of Disease in Childhood, 102(1), 97-102.

Kilbride, H., Aylward, G. P., \& Carter, B. (2018). What are we measuring as outcome? Looking beyond neurodevelopmental impairment. Clinics in Perinatology, 45(3), 467-484.

Koolen, N., Dereymaeker, A., Räsänen, O., Jansen, K., Vervisch, J., Matic, V., De Vos, M., Van Huffel, S., Naulaers, G., \& Vanhatalo, S. (2014). Interhemispheric synchrony in the neonatal EEG revisited: Activation synchrony index as a promising classifier. Frontiers in Human Neuroscience, 8, 1030.

Leon Hernandez, A. (2018). The impact of prematurity on social and emotional development.

Lombroso, C. (1979). Quantified electrographic scales on 10 pre-term healthy newborns followed up to $40-43$ weeks of conceptional age by serial polygraphic recordings. Electroencephalography and Clinical Neurophysiology, 46(4), 460-474.

Luhmann, H., Sinning, A., Yang, J.-W., Reyes-Puerta, V., Stüttgen, M. C., Kirischuk, S., \& Kilb, W. (2016). Spontaneous neuronal activity in developing neocortical networks: From single cells to large-scale interactions. Frontiers in Neural Circuits, 10, 40.

Molnár, Z., Luhmann, H. J., \& Kanold, P. O. (2020). Transient cortical circuits match spontaneous and sensorydriven activity during development. Science, 370(6514).

Odabaee, M., Tokariev, A., Layeghy, S., Mesbah, M., Colditz, P. B., Ramon, C., \& Vanhatalo, S. (2014). Neonatal EEG at scalp is focal and implies high skull conductivity in realistic neonatal head models. Neuroimage, 96, 73-80. 
bioRxiv preprint doi: https://doi.org/10.1101/2021.02.15.431226. this version posted February 18, 2021. The copyright holder for this preprint (which was not certified by peer review) is the author/funder, who has granted bioRxiv a license to display the preprint in perpetuity. It is made available under aCC-BY 4.0 International license.

\section{Phase-based cortical synchrony is affected by prematurity}

Omidvarnia, A., Fransson, P., Metsäranta, M., \& Vanhatalo, S. (2014). Functional bimodality in the brain networks of preterm and term human newborns. Cerebral Cortex, 24(10), 2657-2668.

World Health Organization (2012). Born too soon: The global action report on preterm birth.

Palva, J., Monto, S., Kulashekhar, S., \& Palva, S. (2010). Neuronal synchrony reveals working memory networks and predicts individual memory capacity. Proceedings of the National Academy of Sciences, 107(16), 7580-7585.

Palva, J., Wang, S. H., Palva, S., Zhigalov, A., Monto, S., Brookes, M. J., Schoffelen, J.-M., \& Jerbi, K. (2018). Ghost interactions in MEG/EEG source space: A note of caution on inter-areal coupling measures. Neuroimage, 173, 632-643.

Palva, S., \& Palva, J. M. (2011). Functional roles of alpha-band phase synchronization in local and large-scale cortical networks. Frontiers in Psychology, 2, 204.

Palva, S., \& Palva, J. M. (2012). Discovering oscillatory interaction networks with M/EEG: Challenges and breakthroughs. Trends in Cognitive Sciences, 16(4), 219-230.

Puoliväli, T., Palva, S., \& Palva, J. M. (2020). Influence of multiple hypothesis testing on reproducibility in neuroimaging research: A simulation study and Python-based software. Journal of Neuroscience Methods, 108654.

Räsänen, O., Metsäranta, M., \& Vanhatalo, S. (2013). Development of a novel robust measure for interhemispheric synchrony in the neonatal EEG: Activation synchrony index (ASI). Neuroimage, 69,

615 Rogers, E., \& Hintz, S. R. (2016). Early neurodevelopmental outcomes of extremely preterm infants. Seminars in Perinatology, 40(8), 497-509.

617 Sahin, M., Sweeney, J. A., \& Jones, S. R. (2020). Biomarkers to Enable Therapeutics Development in Neurodevelopmental Disorders. Frontiers in Integrative Neuroscience.

619 Siebenhühner, F., Wang, S. H., Palva, J. M., \& Palva, S. (2016). Cross-frequency synchronization connects networks of fast and slow oscillations during visual working memory maintenance. Elife, 5, e13451.

Stevenson, N., Oberdorfer, L., Tataranno, M.-L., Breakspear, M., Colditz, P. B., de Vries, L. S., Benders, M. J., Klebermass-Schrehof, K., Vanhatalo, S., \& Roberts, J. A. (2020). Automated cot-side tracking of functional brain age in preterm infants. Annals of Clinical and Translational Neurology.

624 Stjerna, S., Sairanen, V., Gröhn, R., Andersson, S., Metsäranta, M., Lano, A., \& Vanhatalo, S. (2015). Visual fixation in human newborns correlates with extensive white matter networks and predicts long-term neurocognitive development. Journal of Neuroscience, 35(12), 4824-4829. 
bioRxiv preprint doi: https://doi.org/10.1101/2021.02 15.431226. this version posted February 18, 2021. The copyright holder for this preprint (which was not certified by peer review) is the author/funder, who has granted bioRxiv a license to display the preprint in perpetuity. It is made available under aCC-BY 4.0 International license.

\section{Phase-based cortical synchrony is affected by prematurity}

Tadel, F., Baillet, S., Mosher, J. C., Pantazis, D., \& Leahy, R. M. (2011). Brainstorm: A user-friendly application for MEG/EEG analysis. Computational Intelligence and Neuroscience, 2011.

Tewarie, P., Hunt, B. A., O’Neill, G. C., Byrne, A., Aquino, K., Bauer, M., Mullinger, K. J., Coombes, S., \& Brookes, M. J. (2019). Relationships between neuronal oscillatory amplitude and dynamic functional connectivity. Cerebral Cortex, 29(6), 2668-2681.

Tharp, B. (1990). Electrophysiological brain maturation in premature infants: An historical perspective. Journal of Clinical Neurophysiology: Official Publication of the American Electroencephalographic Society, 7(3), 302-314.

Tokariev, A., Roberts, J. A., Zalesky, A., Zhao, X., Vanhatalo, S., Breakspear, M., \& Cocchi, L. (2019a). Largescale brain modes reorganize between infant sleep states and carry prognostic information for preterms. Nature Communications, 10(1), 1-9.

Tokariev, A., Stjerna, S., Lano, A., Metsäranta, M., Palva, J. M., \& Vanhatalo, S. (2019b). Preterm birth changes networks of newborn cortical activity. Cerebral Cortex, 29(2), 814-826.

Tokariev, A., Vanhatalo, S., \& Palva, J. M. (2016a). Analysis of infant cortical synchrony is constrained by the number of recording electrodes and the recording montage. Clinical Neurophysiology, 127(1), 310-323.

Tokariev, A., Videman, M., Palva, J. M., \& Vanhatalo, S. (2016b). Functional Brain Connectivity Develops Rapidly Around Term Age and Changes Between Vigilance States in the Human Newborn. Cerebral Cortex, 26(12), 4540-4550. https://doi.org/10.1093/cercor/bhv219

Tóth, B., Urbán, G., Haden, G. P., Márk, M., Török, M., Stam, C. J., \& Winkler, I. (2017). Large-scale network organization of EEG functional connectivity in newborn infants. Human Brain Mapping, 38(8), 40194033.

Toulmin, H., O'Muircheataigh, J., Counsell, S. J., Falconer, S., Chew, A., Beckmann, C. F., \& Edwards, A. D. (2020). Functional thalamocortical connectivity at term equivalent age and outcome at 2 years in infants born preterm. Cortex.

Tremblay, P., \& Dick, A. S. (2016). Broca and Wernicke are dead, or moving past the classic model of language neurobiology. Brain and Language, 162, 60-71.

Vanhatalo, S., \& Kaila, K. (2006). Development of neonatal EEG activity: From phenomenology to physiology. Seminars in Fetal and Neonatal Medicine, 11(6), 471-478.

Vanhatalo, S., Palva, J. M., Andersson, S., Rivera, C., Voipio, J., \& Kaila, K. (2005). Slow endogenous activity transients and developmental expression of $\mathrm{K}+-\mathrm{Cl}-$ cotransporter 2 in the immature human cortex. European Journal of Neuroscience, 22(11), 2799-2804.

Vidaurre, D., Hunt, L. T., Quinn, A. J., Hunt, B. A., Brookes, M. J., Nobre, A. C., \& Woolrich, M. W. (2018). Spontaneous cortical activity transiently organises into frequency specific phase-coupling networks. Nature Communications, 9(1), 1-13. 
bioRxiv preprint doi: https:/doi org/10.1101/2021.02 15.431226; this version posted February 18,2021 . The copyright holder for this

preprint (which was not certified by peer review) is the author/funder, who has granted bioRxiv a license to display the preprint in perpetuity. It is made available under aCC-BY 4.0 International license.

\section{Phase-based cortical synchrony is affected by prematurity}

663 Vinck, M., Oostenveld, R., Van Wingerden, M., Battaglia, F., \& Pennartz, C. M. (2011). An improved index of phase-synchronization for electrophysiological data in the presence of volume-conduction, noise and sample-size bias. Neuroimage, 55(4), 1548-1565.

666

Vollmer, B., Lundequist, A., Mlaartensson, G., Nagy, Z., Lagercrantz, H., Smedler, A.-C., \& Forssberg, H. (2017). Correlation between white matter microstructure and executive functions suggests early developmental influence on long fibre tracts in preterm born adolescents. PloS One, 12(6), e0178893.

669 Womelsdorf, T., Schoffelen, J.-M., Oostenveld, R., Singer, W., Desimone, R., Engel, A. K., \& Fries, P. (2007). Modulation of neuronal interactions through neuronal synchronization. Science, 316(5831), 1609-1612

671 Xia, M., Wang, J., \& He, Y. (2013). BrainNet Viewer: A network visualization tool for human brain connectomics. PloS One, 8(7), e68910.

673 Yu, M., Engels, M. M., Hillebrand, A., Van Straaten, E. C., Gouw, A. A., Teunissen, C., Van Der Flier, W. M., Scheltens, P., \& Stam, C. J. (2017). Selective impairment of hippocampus and posterior hub areas in Alzheimer's disease: An MEG-based multiplex network study. Brain, 140(5), 1466-1485.

676 Zalesky, A., Fornito, A., \& Bullmore, E. T. (2010). Network-based statistic: Identifying differences in brain networks. Neuroimage, 53(4), 1197-1207.

678 
681

AS

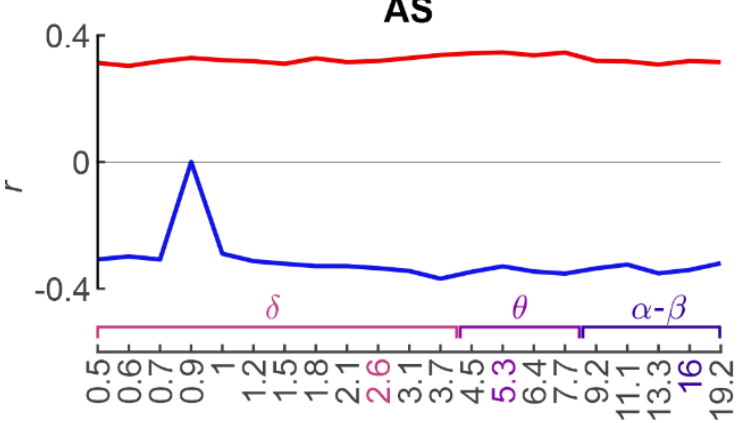

QS

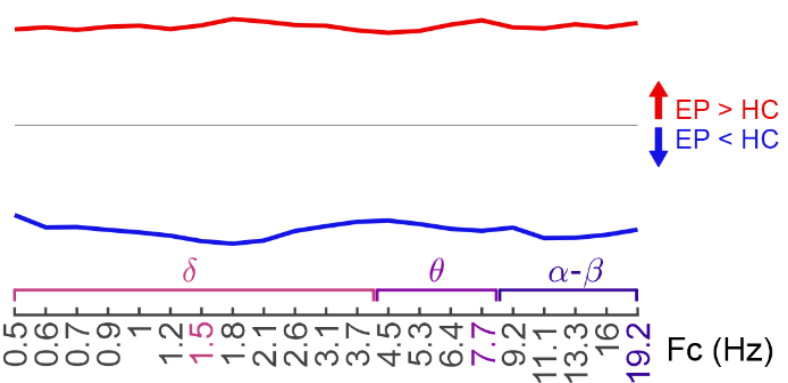

683

684 Figure 2-figure supplement 1. Effect size of the statistical group differences on cortical

685 PPC networks. The effect size, computed by the mean rank-biserial correlation $(r)$ of the 686 significant networks shown in Figure 1 (two one-tailed Wilcoxon rank sum tests, $\alpha=0.01$ )

687 during active sleep (AS, left) and quiet sleep (QS, right), as a function of frequency. Networks 688 with increased connectivity strength in EP $(E P>H C)$ are shown in red, and networks with 689 decreased connectivity in EP $(\mathrm{EP}<\mathrm{HC})$ are displayed in blue. 

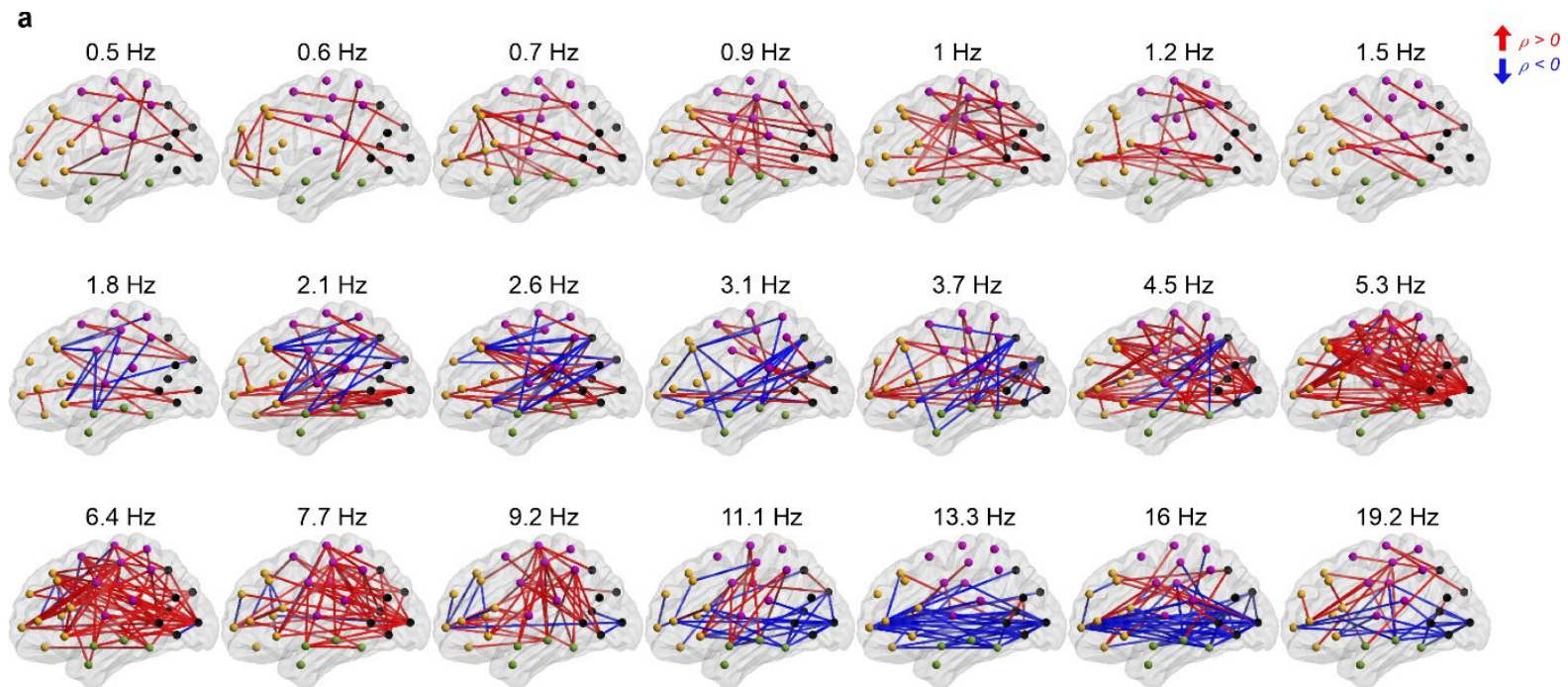

690

b
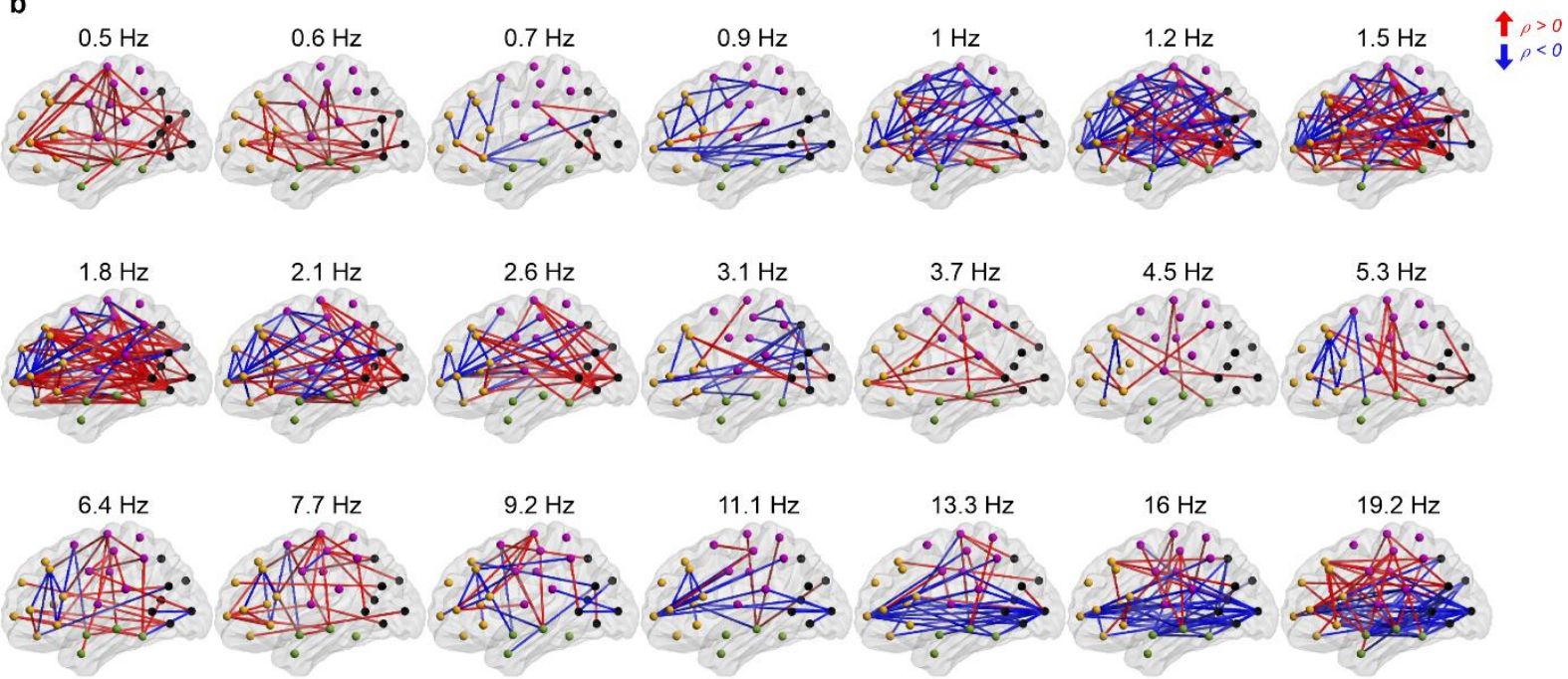

693 Figure 2-figure supplement 2. Effects of prematurity on cortical PPC networks modulate

694 over frequency. Spatial visualizations of the group difference networks obtained from network

695 density measurements (Figure 1 , two one-tailed Wilcoxon rank sum tests, $\alpha=0.01$ ) over all

696 frequency bands in AS (a) and QS (b). Only the edges which passed FDR correction $(q=$

697 0.01) are shown. Red networks display connections of increased connectivity in $\mathrm{EP}(\mathrm{EP}>\mathrm{HC})$ and blue networks reduced connectivity in EP $(\mathrm{EP}<\mathrm{HC})$. 
a

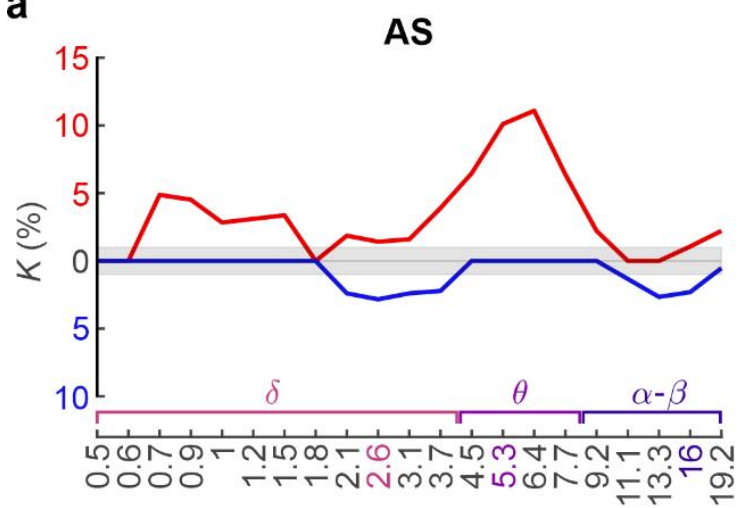

b
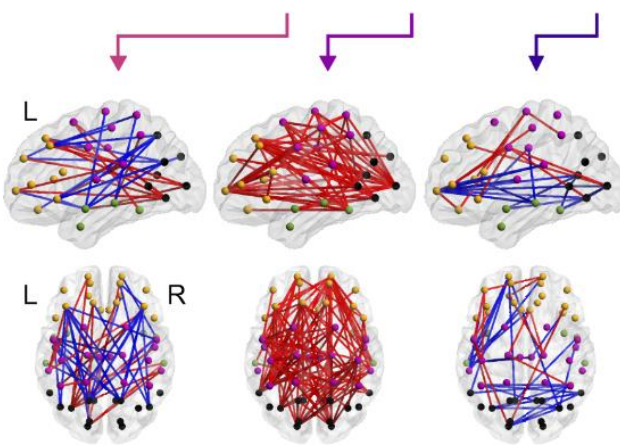

QS
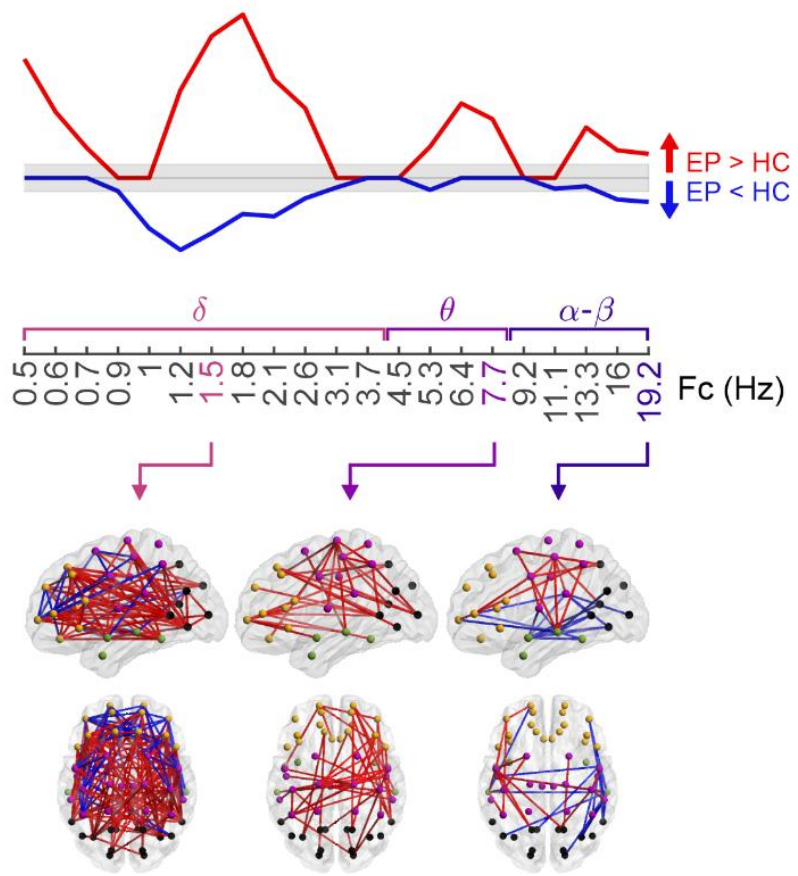

Figure 2-figure supplement 3. Effects of prematurity on cortical PPC networks replicated

with an independent additional analysis. (a) Network density (K) of PPC group difference level $\alpha=0.05,5000$ permutations) is shown for AS (left) and QS (right) as a function of frequency bands, denoted by their central frequencies. The directions of difference (EP $>\mathrm{HC}$ or $\mathrm{EP}<\mathrm{HC}$ ) are indicated in red and blue, respectively. (b) 3-dimensional visualizations present the spatial distribution of group difference networks at the frequencies selected from

Figure 1. The direction of difference is indicated as in (a). 

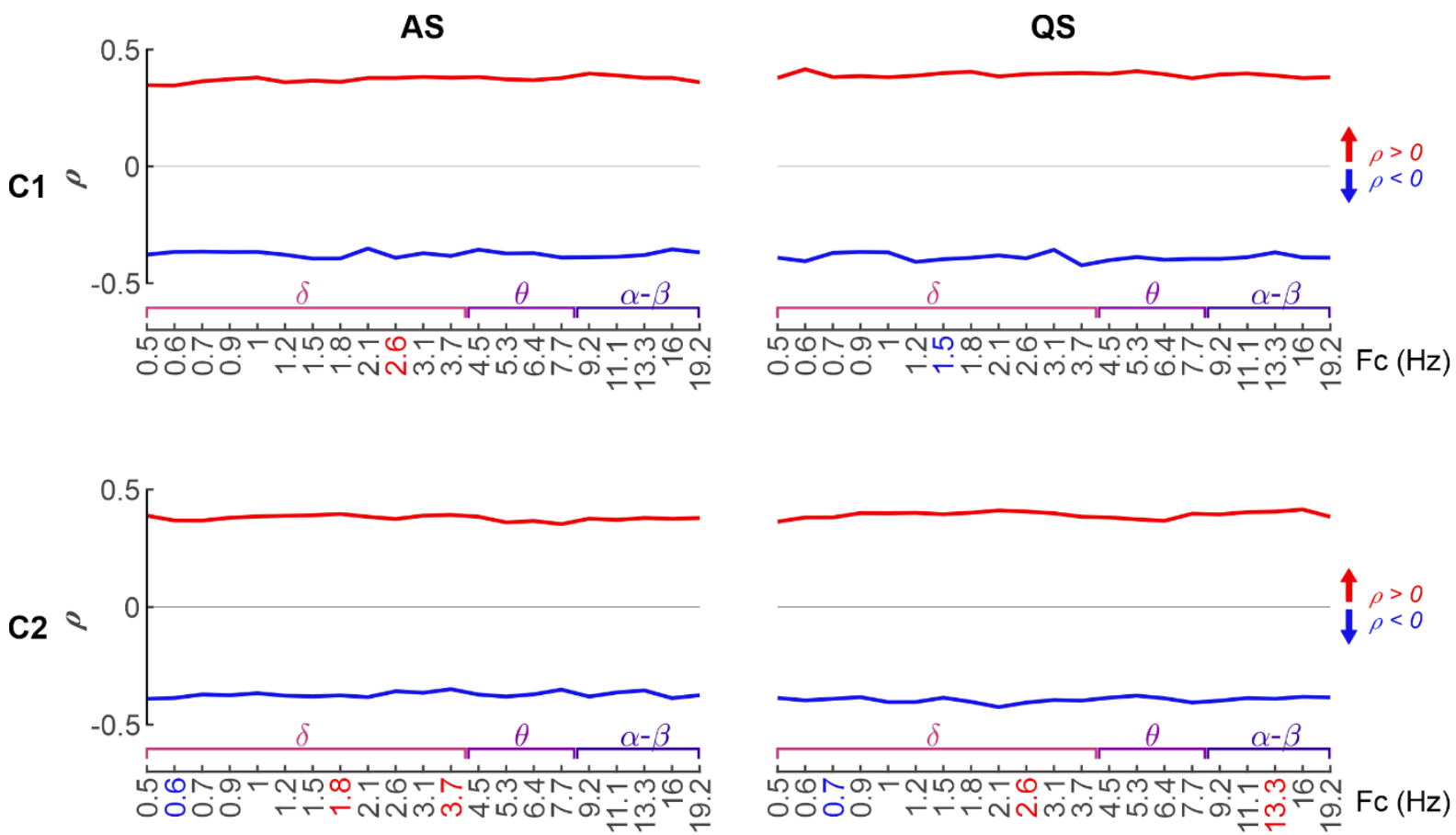

711 Figure 3-figure supplement 1. Effect size of PPC networks depicting clinical correlation.

712 The effect size, acquired from the mean Spearman (two-tailed test, with conceptional age as

713 a covariate, and $\alpha=0.05) \rho$-value of the positive $(\rho \geq 0$, red) and negative $(\rho<0$, blue)

714 networks, as a function of frequency band. The results are presented for active sleep (AS, left)

715 and quiet sleep (QS, blue), as well as for the neurological outcome scores C1 (above) and C2

716 (below). 

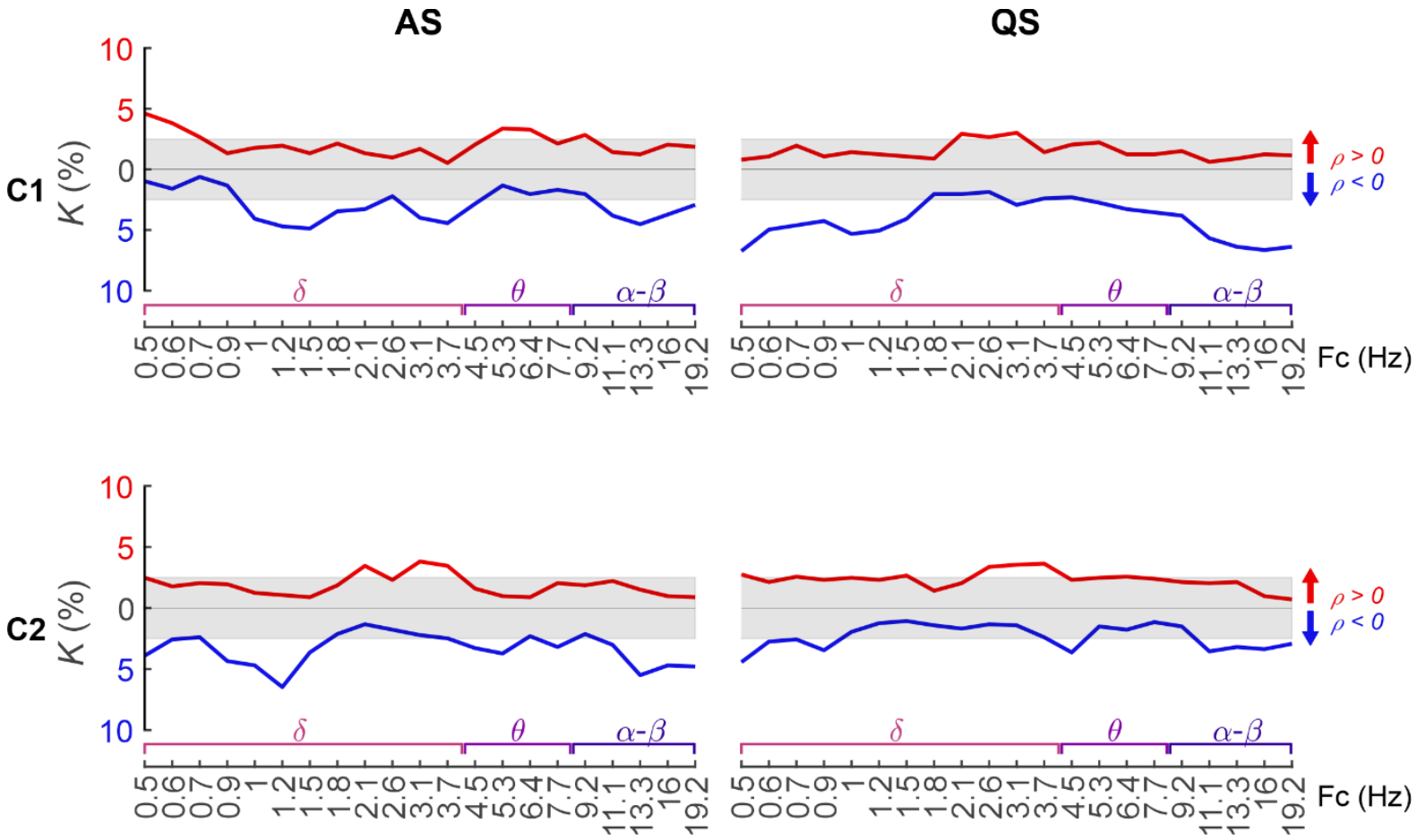

718

Figure 3-figure supplement 2. Absence of correlation between cortical PPC strengths

and early neurological performance in healthy controls. Network density $(K)$ of PPC

correlation related to the neurological assessment scores $\mathrm{C} 1$ and $\mathrm{C} 2$ as a function of frequency band in the HC cohort (Spearman, two-tailed test, with conceptional age as a covariate, and $\alpha=0.05)$. The FDR $(q=0.05)$ boundaries are depicted as a grey shaded area.

Colour coding represents the polarity of the correlation (red: $\rho \geq 0$, blue $\rho<0$ ). Analysis of the $\mathrm{HC}$ group shows an absence of wider network patterns that would correlate positively to either of the neurological scores. There are some networks at low frequencies with negative correlation to $\mathrm{C} 1$ and $\mathrm{C} 2$ during $\mathrm{AS}$ (peak at $\mathrm{Fc}=1.2-1.5 \mathrm{~Hz}$ ) and some networks at low and high frequencies with negative correlation to $\mathrm{C} 1$ during QS (peaks at $\mathrm{Fc}=0.5 \mathrm{~Hz}$ and $\mathrm{Fc}=16$ $\mathrm{Hz})$. 

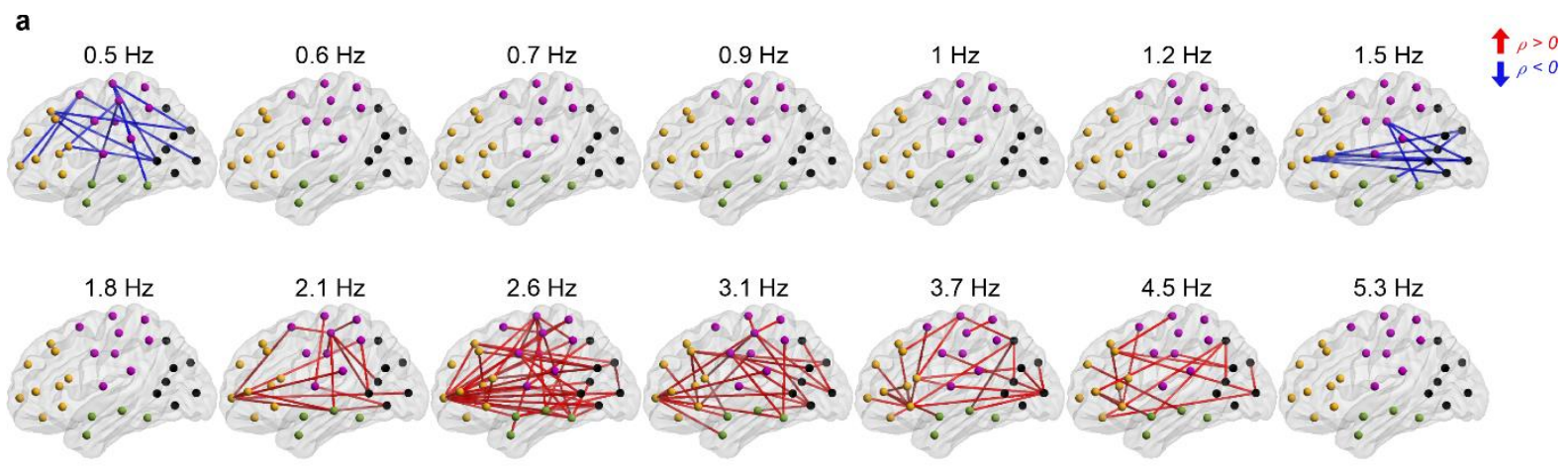

$5.3 \mathrm{~Hz}$
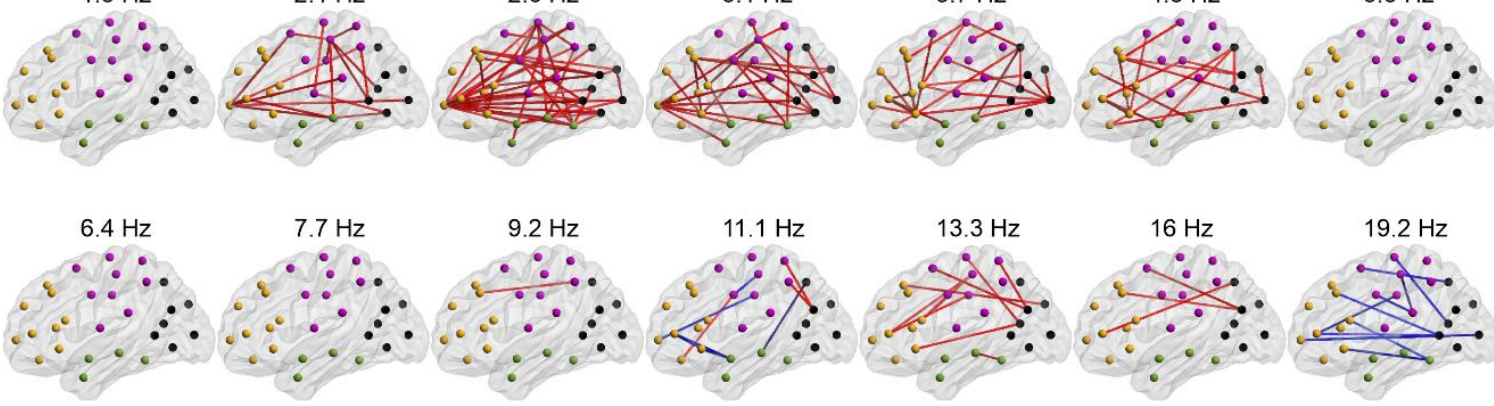

b
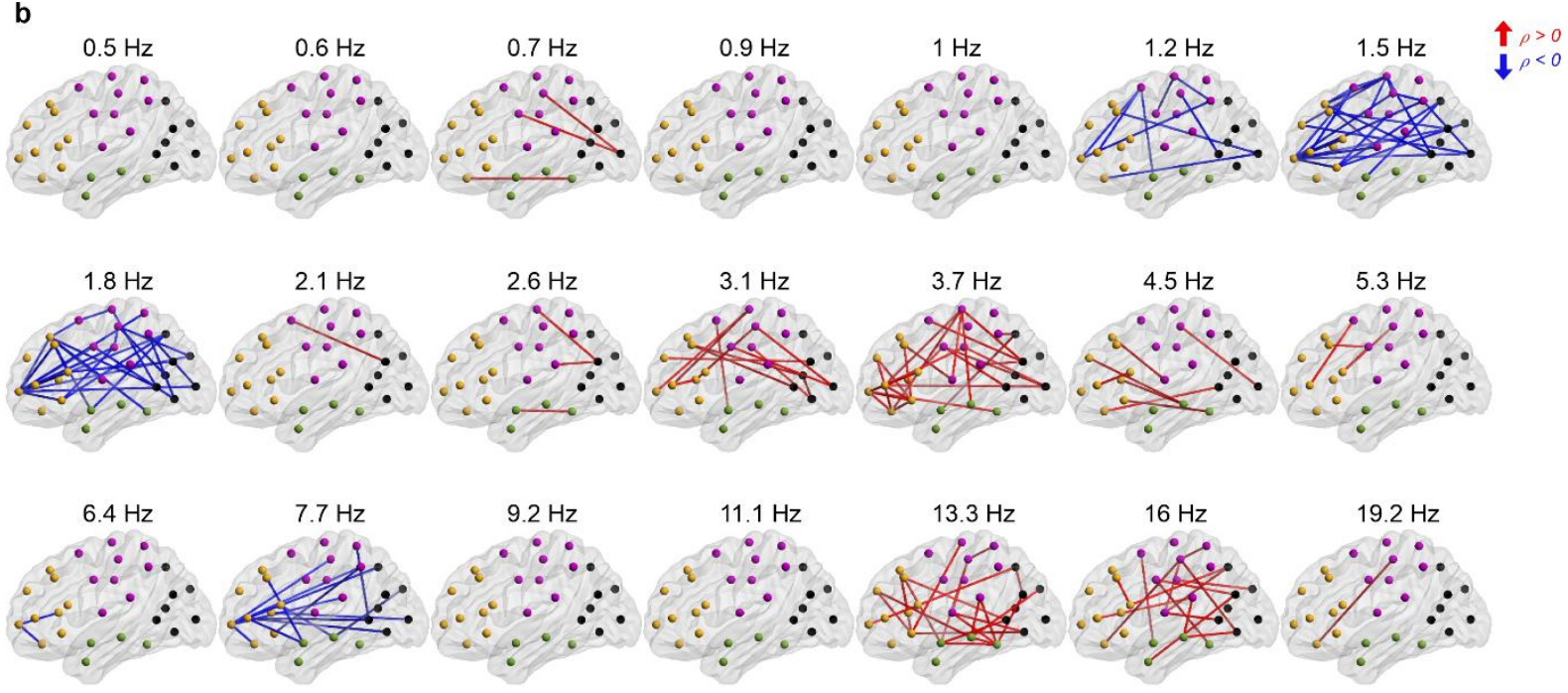

Figure 3-figure supplement 3. The frequency-specific PPC correlation networks to $\mathbf{C} 1$

neurological outcomes. 3-dimensional visualizations depicting the correlation of connection strength to $\mathrm{C} 1$ scores (Spearman, two-tailed test, with conceptional age as a covariate, and $\alpha$ $=0.05)$ on all investigated frequency bands in AS equivalent age. The edges displayed in the figure passed FDR correction $(q=0.05)$. Red networks indicate positive correlation (Spearman $\rho \geq 0$ ), whereas blue connections express negative correlation (Spearman $\rho<0$ ). 

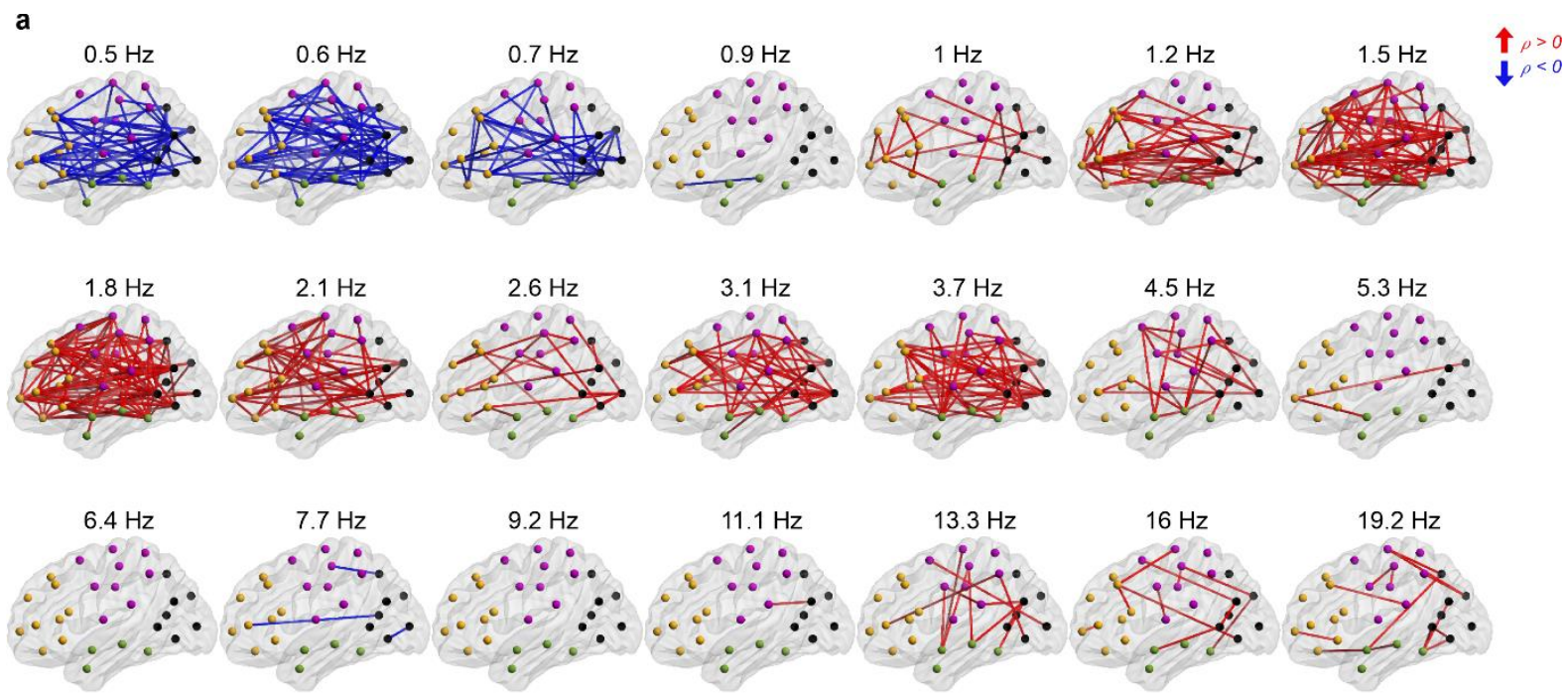

b
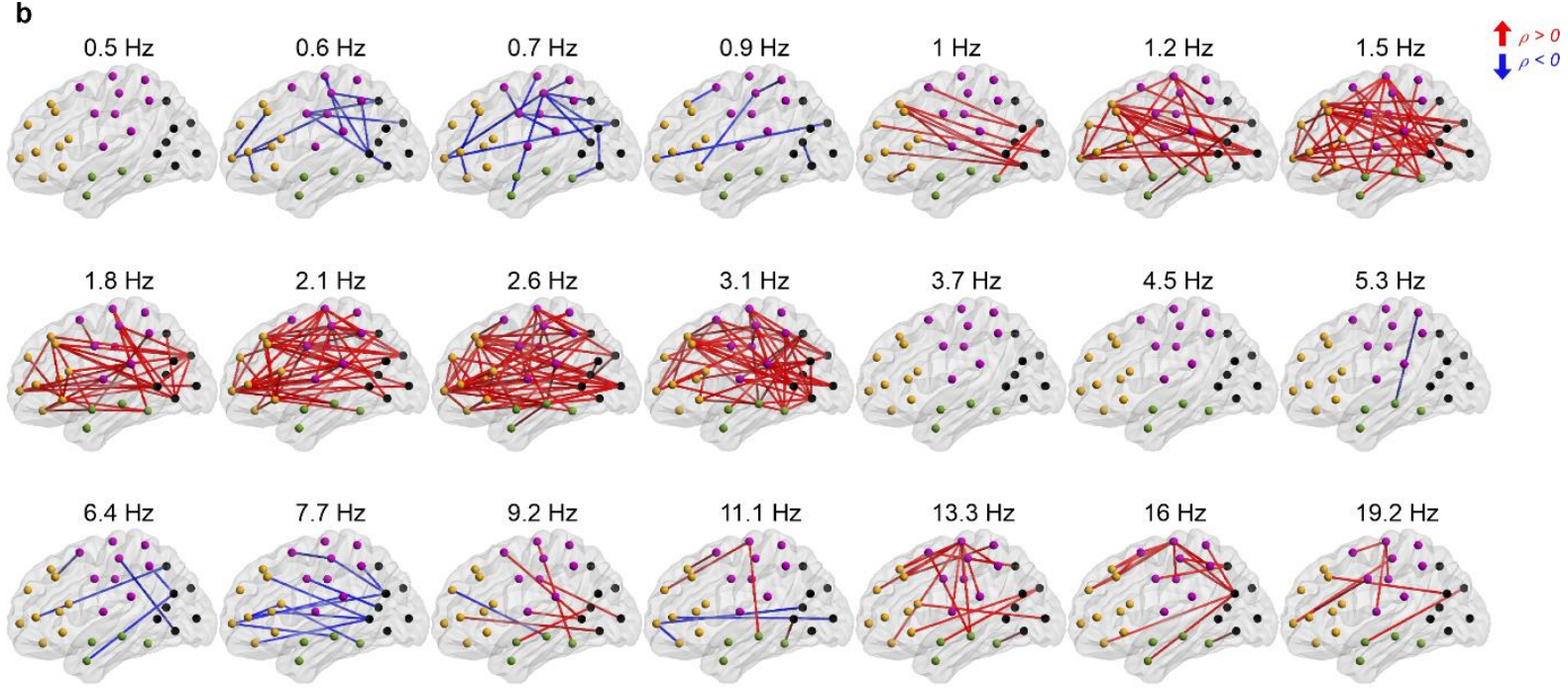

743 Figure 3-figure supplement 4. The frequency-specific PPC correlation networks to C2

neurological outcomes. 3-dimensional visualizations depicting the correlation of connection strength to C2 scores (Spearman, two-tailed test, with conceptional age as a covariate, and $\alpha$ $=0.05)$ on all investigated frequency bands in AS

747 equivalent age. The edges displayed in the figure passed FDR correction $(q=0.05)$. Red networks indicate positive correlation (Spearman $\rho \geq 0$ ), whereas blue connections express negative correlation (Spearman $\rho<0$ ). 

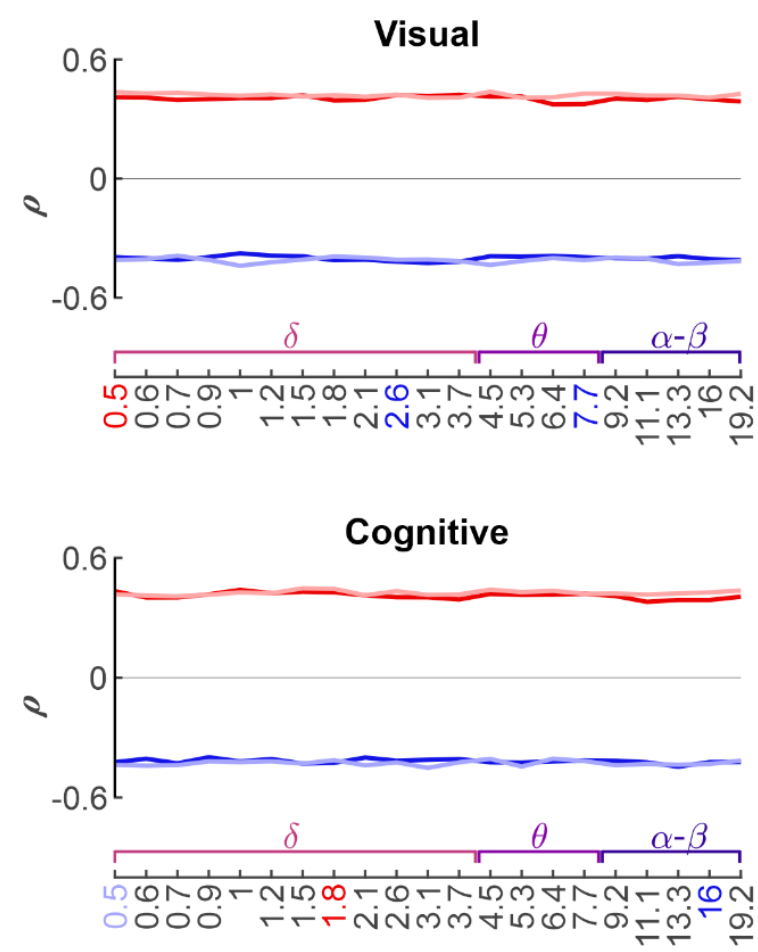

Motor

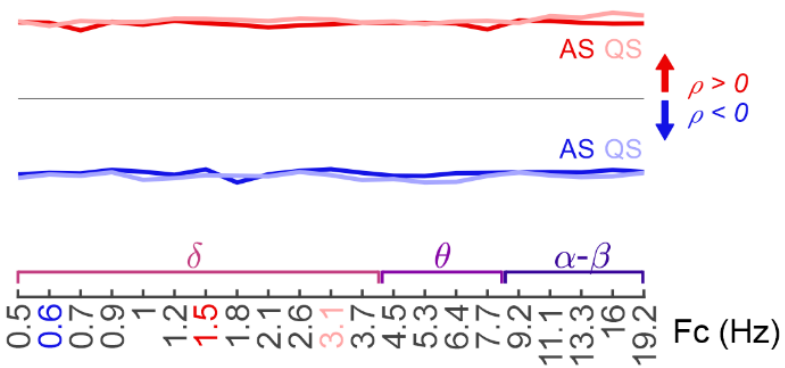

Language Comprehension

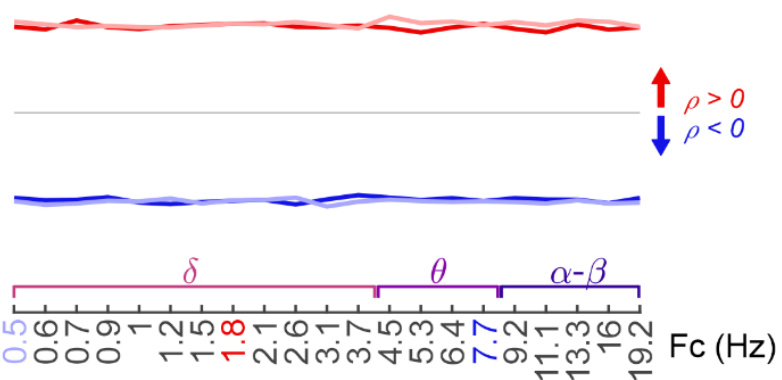

Figure 4-figure supplement 1. Effect size of PPC networks depicting long-term

neurocognitive correlation. The effect size was computed as the mean Spearman (twotailed test, with conceptional age as a covariate, and $\alpha=0.05) \rho$-value for the significant networks of each frequency band. The colors show the sign of the correlation $(\rho \geq 0$ : red and $\rho<0$ : blue). The effect size values are presented separately for active sleep (AS, dark hues) and quiet sleep (QS, light hues) as well as for the neurocognitive scores Griffiths visual (upper left), Griffiths motor (upper right), Bayley cognitive (lower left), and Bayley language comprehension (lower right). 
a
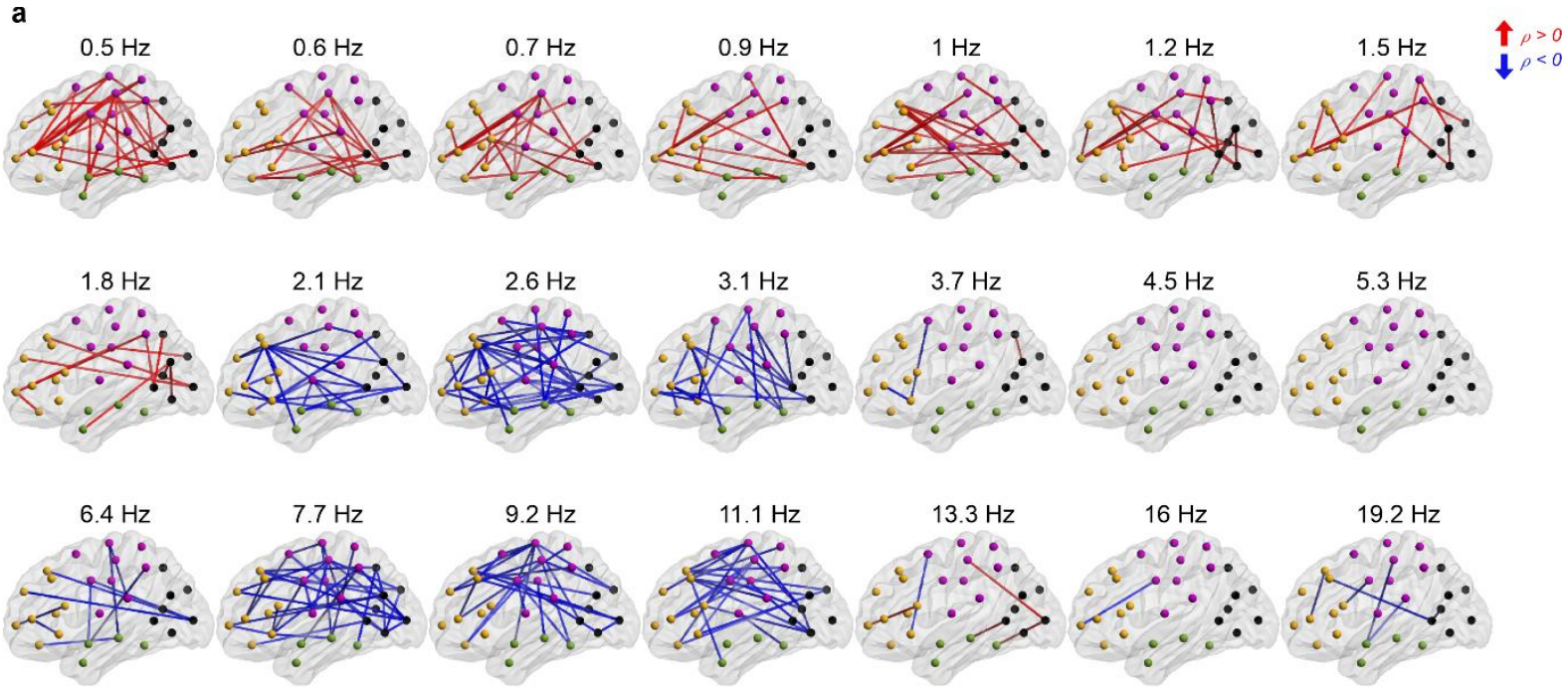

b
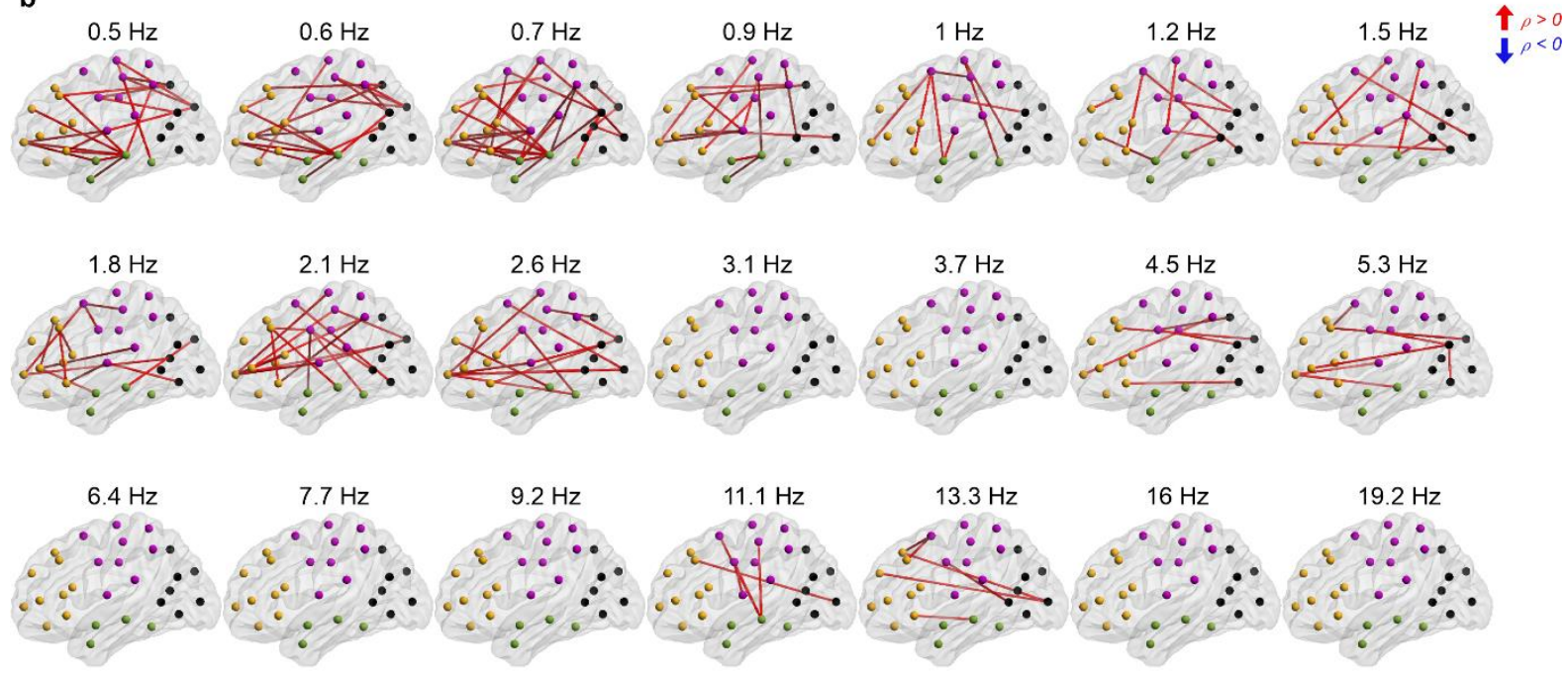

$19.2 \mathrm{~Hz}$

Figure 4-figure supplement 2. The frequency-selective PPC fingerprint networks

reflecting visual performance at 2 years of age. Spatial visualizations of PPC edge strength correlation to Griffiths visual scores (Spearman, two-tailed test, with conceptional age as a

(b) in the EP cohort at 2 years of age. The presented connections survived multiple comparisons correction with FDR $(q=0.05)$. Colour coding represents the sign of correlation (red: $\rho \geq 0$, blue $\rho<0)$. 
a
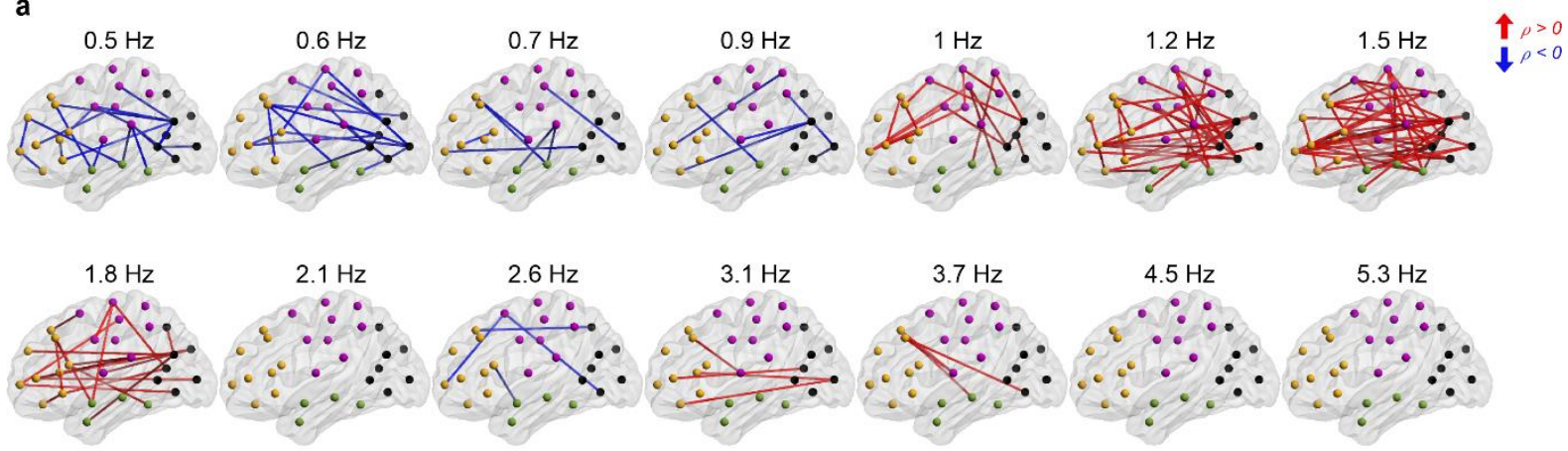

$5.3 \mathrm{~Hz}$
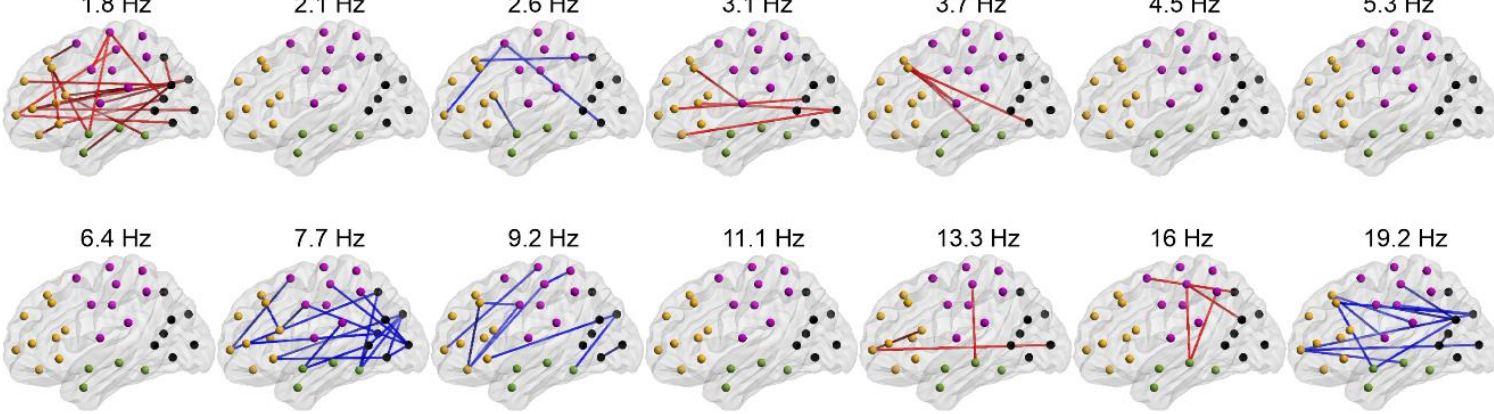

b
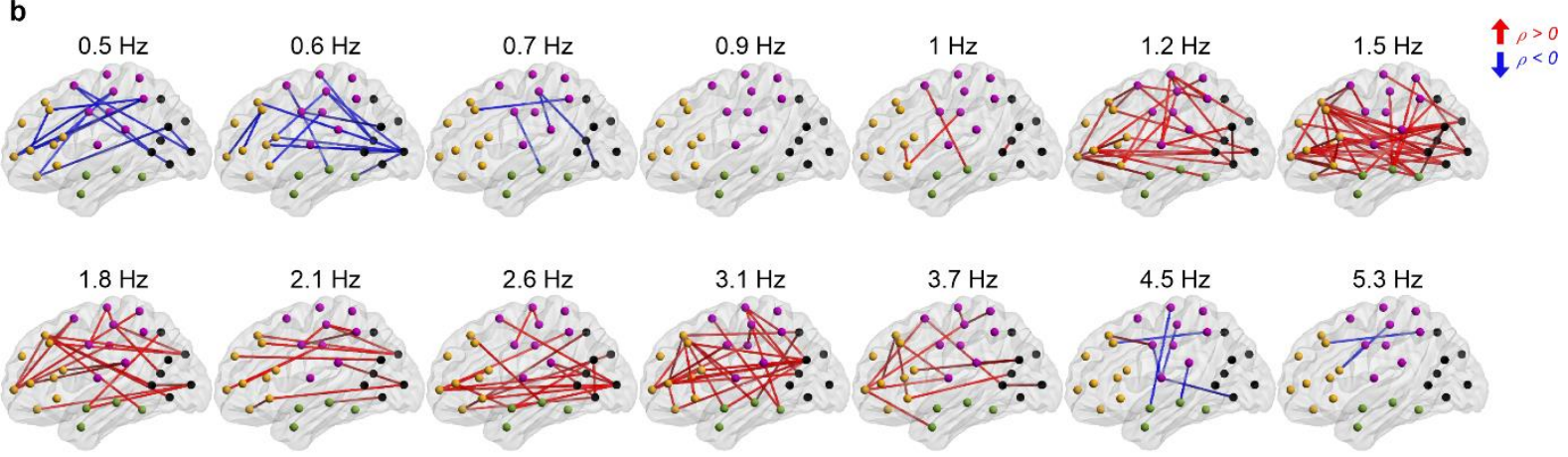

$5.3 \mathrm{~Hz}$
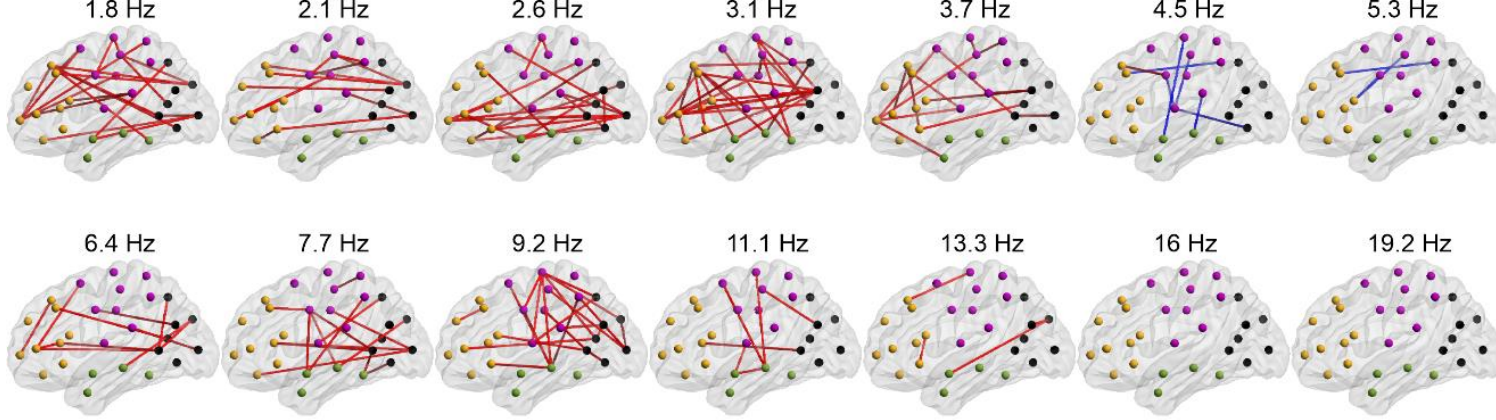

$19.2 \mathrm{~Hz}$

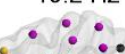

772 Figure 4-figure supplement 3. The frequency-selective PPC fingerprint networks correlation to Griffiths motor scores (Spearman, two-tailed test, with conceptional age as a FDR $(q=0.05)$. Colour coding represents the sign of correlation (red: $\rho \geq 0$, blue $\rho<0$ ). 
a
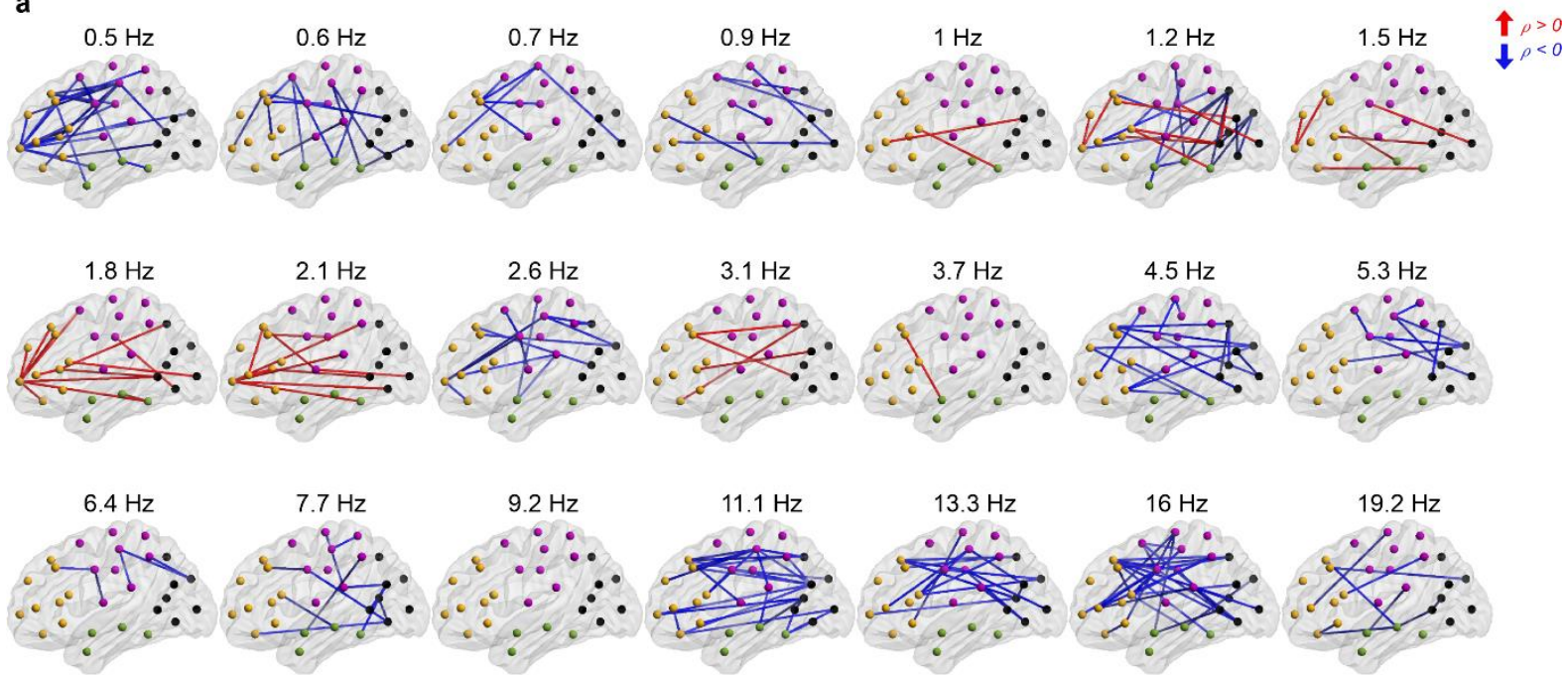

b
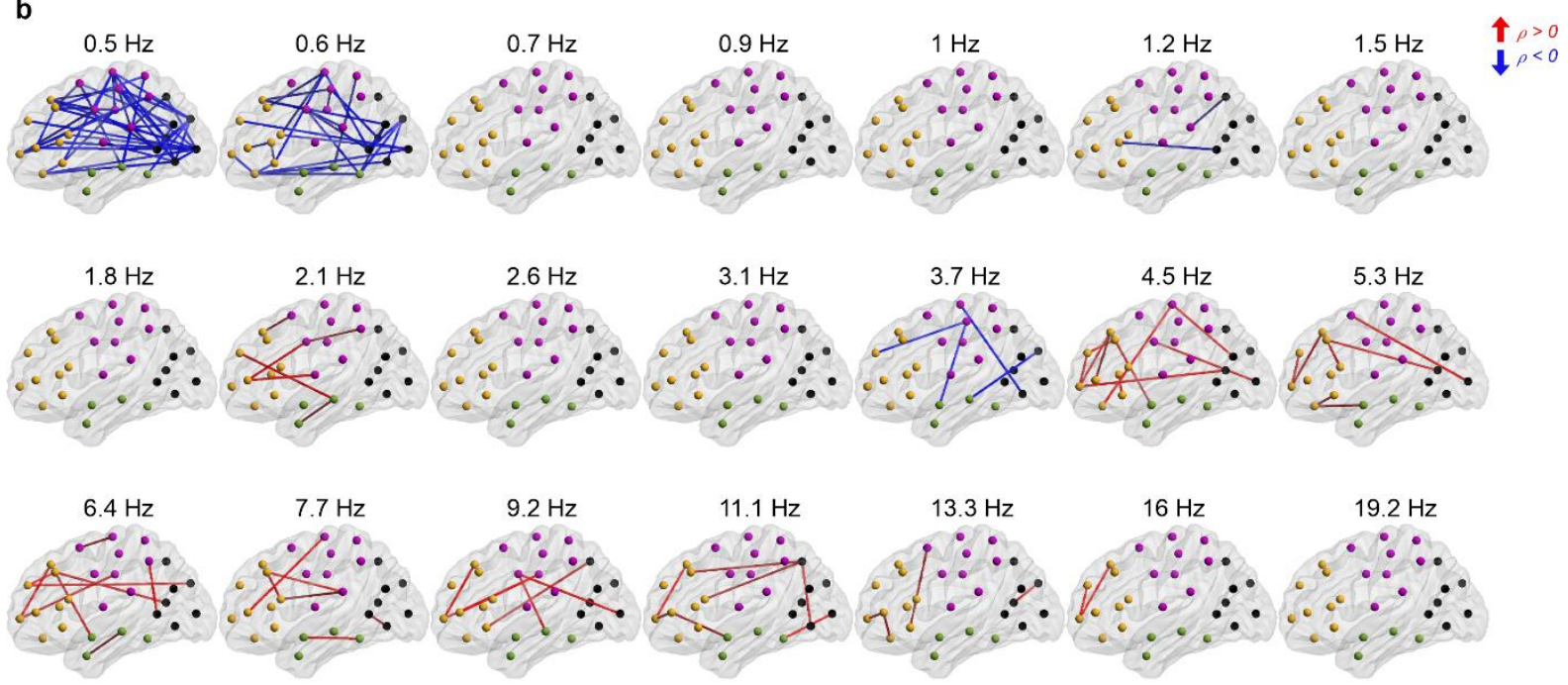

Figure 4-figure supplement 4. The frequency-selective PPC fingerprint networks

reflecting cognitive performance at 2 years of age. Spatial visualizations of PPC edge strength correlation to Bayley cognitive scores (Spearman, two-tailed test, with conceptional age as a covariate, and 0.05) over all examined frequency bands in AS (a) and QS (b) in the EP cohort at 2 years of age. The presented connections survived multiple comparisons correction with FDR $(q=0.05)$. Colour coding represents the sign of correlation (red: $\rho \geq 0$, blue $\rho<0$ ). 
a
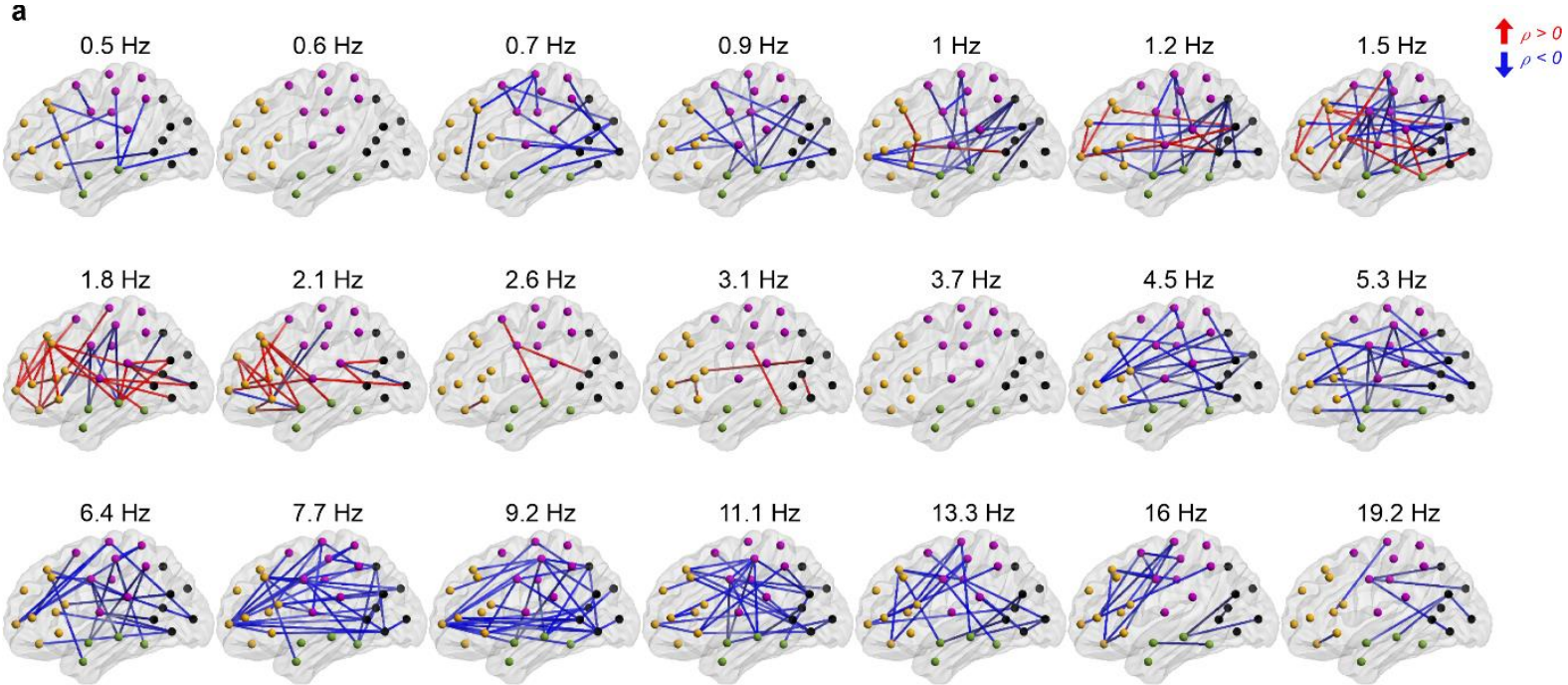

$19.2 \mathrm{~Hz}$

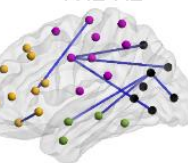

b
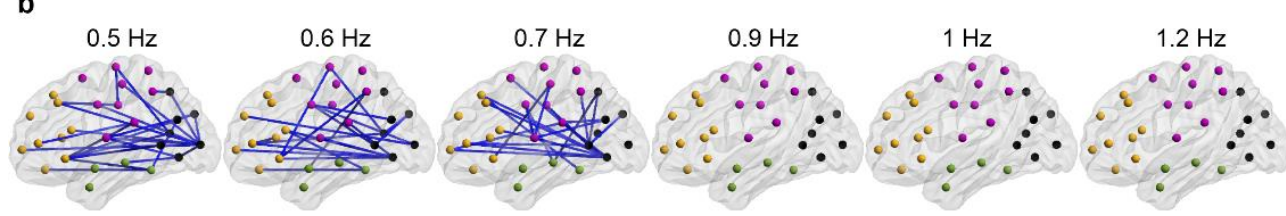

$1.5 \mathrm{~Hz}$

$\uparrow \rho>0$
$\downarrow \rho<0$
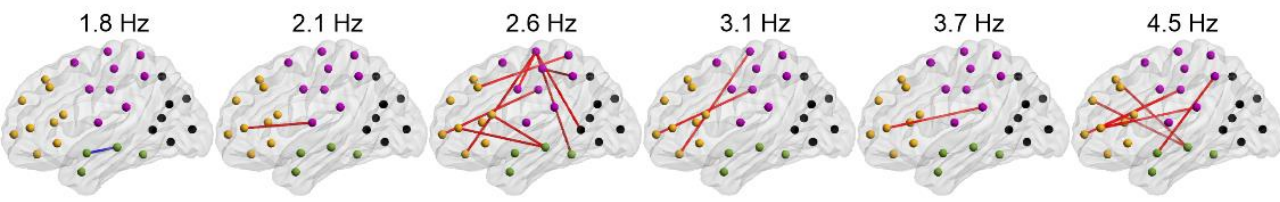

$5.3 \mathrm{~Hz}$
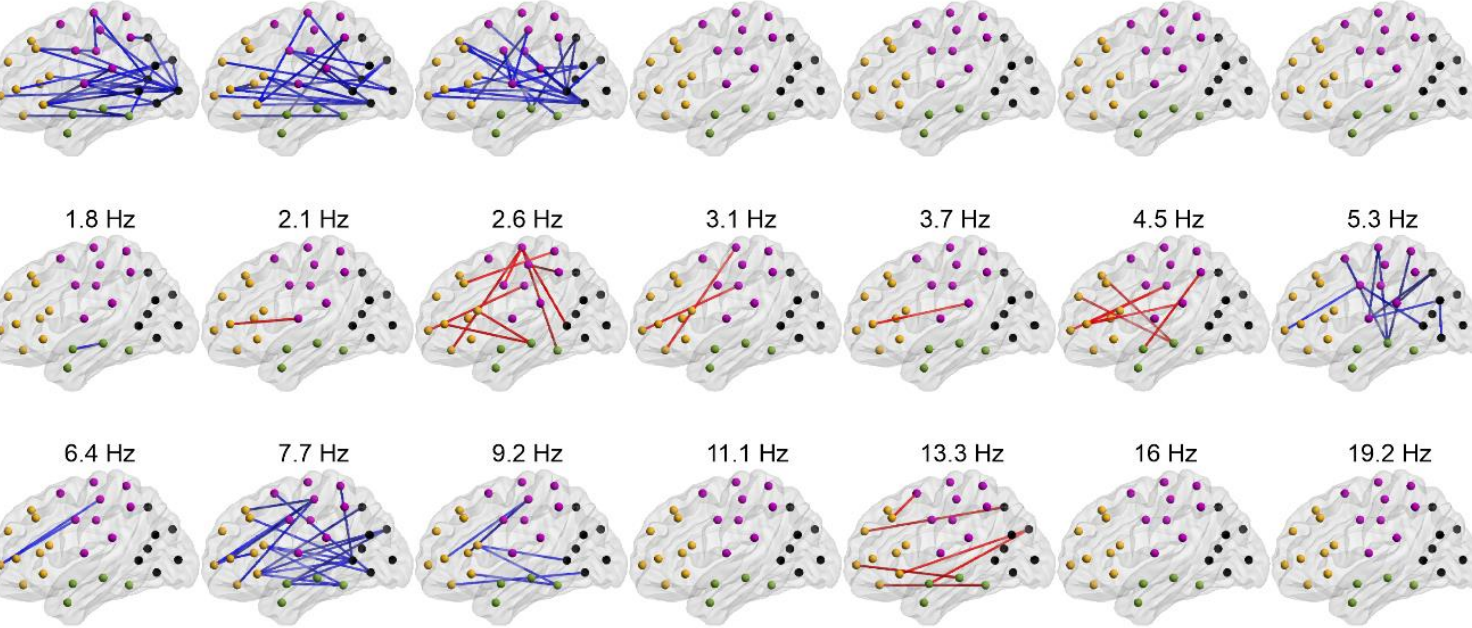

$11.1 \mathrm{~Hz}$
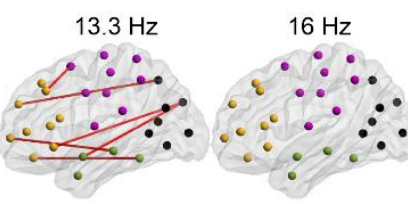

19. $2 \mathrm{~Hz}$
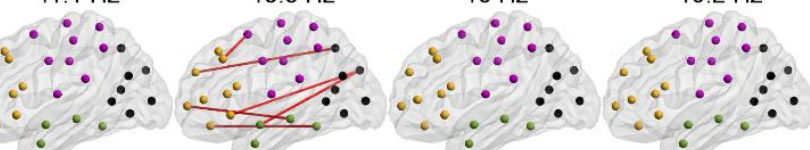

Figure 4-figure supplement 5. The frequency-selective PPC fingerprint networks

reflecting language comprehension at $\mathbf{2}$ years of age. Spatial visualizations of PPC edge strength correlation to Bayley language comprehension scores (Spearman, two-tailed test, and QS (b) in the EP cohort at 2 years of age. The presented connections survived multiple (red: $\rho \geq 0$, blue $\rho<0$ ). 